« Accountability and Transparency about Central Bank Preferences for Model Robustness »

\author{
$\underline{\text { Auteurs }}$ \\ Meixing Dai, Eleftherios Spyromitros
}

Document de Travail $n^{\circ} 2009$ - 18

Mai 2009

Faculté des sciences économiques et de gestion Pôle européen de gestion et d'économie (PEGE) 61 avenue de la Forêt Noire F-67085 Strasbourg Cedex

Secétariat du BETA Géraldine Manderscheidt Tél. : (33) 0390242069 Fax : (33) 0390242070 g.manderscheidt@unistra.fr http://cournot2.u-strasbg.fr/beta 


\title{
Accountability and Transparency about Central Bank Preferences for Model Robustness
}

\author{
Meixing DAI ${ }^{*}$ \\ Eleftherios SPYROMITROS **
}

\begin{abstract}
Using a New Keynesian model subject to misspecifications, we examine the accountability issue in a framework of delegation where government and private agents are uncertain about the central bank's preference for model robustness. We show that, in the benchmark case of full transparency, the optimal inflation targeting weight (or penalty) is decreasing with the preference for robustness. Departing from the benchmark equilibrium, the central bank has then incentive to be less transparent in order to reduce the optimal inflation targeting weight and thus to become more independent vis-à-vis the government. We also find that greater opacity will increase the sensibility of inflation and model misspecification to the inflation shock but will decrease that of output-gap. Since macroeconomic volatility could be increased or decreased under more opacity, there could exist in some cases a trade-off between the level and the variability of inflation (and output gap). Persistent inflation shocks could be associated with a higher inflation targeting weight as well as a higher sensibility of inflation and output gap to the inflation shock but a lower sensibility of model misspecification.
\end{abstract}

Keywords: Central bank accountability, model uncertainty, monetary policy transparency.

JEL Classification: E42, E52, E58.

\footnotetext{
* University of Strasbourg, BETA-Theme, 61, avenue de la Forêt Noire - 67085 Strasbourg CedexFrance. Phone: (+33) 03902421 31; Fax: (+33) 03902420 71; e-mail: dai@cournot.u-strasbg.fr.

** University of Strasbourg, BETA-Theme, 61, avenue de la Forêt Noire - 67085 Strasbourg Cedex France; Phone: (+33) 03902420 94; Fax: (+33) 03902420 71; e-mail: spyro@cournot.ustrasbg.fr.
}

Acknowledgments: We are very grateful to two anonymous referees for constructive comments on a previous version of this paper. 


\section{Introduction}

The New-Keynesian approach to macroeconomic modelling is used extensively in the monetary policy literature for almost a decade now. It has produced several important insights in the analysis of monetary policy and is now commonly applied to provide policy prescriptions (Clarida et al., 1999). Most of the studies focus on specific topics and stay unconnected between them. In particular, recent developments on optimal monetary policy in forward-looking models have explored separately various notions of transparency and model robustness. ${ }^{1}$

Several studies examine issues related to monetary policy transparency in the NewKeynesian framework, while assuming that the central bank knows the true structure of the economy. Cukierman (2002) has demonstrated that it may be rational for the central bank to de-emphasize a high flexibility parameter and asymmetric preferences that might raise inflationary expectations. For Jensen (2002), greater transparency about control errors means that policy has a larger impact on future expectations and, via this channel, on current equilibrium inflation. This leads the central bank to be less aggressive in its policy actions. Eijffinger and Tesfaselassie (2007) find that, in the absence of uncertainty about the central bank's targets, advance disclosure of central bank's private information on future shocks impairs stabilization of current inflation and output.

To the difference of previous studies, Walsh (2003) introduces accountability issues through an incentive scheme that puts a weight on the inflation target objective of the central bank. He has shown that the fundamental trade-off between accountability and stabilization

\footnotetext{
${ }^{1}$ Pioneered by Cukierman and Metzler (1986), transparency issue has been examined in other types of models both theoretically and empirically by Nolan and Schaling (1998), Faust and Svensson (2001), Chortareas et al. (2002), Eijffinger and Geraats (2006), Demertzis and Hughes Hallet (2007), among others.
} 
depends on the degree of transparency concerning the central bank's output-gap target, defined as the ability to monitor the central bank’s performance.

Nevertheless, as any model, New-Keynesian models rest on a set of assumptions that may or may not be good approximations of economies. Without the possibility of having a complete description of reality, a policymaker is likely to prefer basing policy on principles that are also valid if the assumptions on which the model is founded differ from reality. In other words, policy prescriptions should be robust to reasonable deviations from the benchmark model.

The literature on monetary policy robustness has been mainly developed into two directions. The first one leads to what has been called robustly optimal instrument rules (Svensson and Woodford, 2004; Giannoni and Woodford, 2003a, 2003b). As these instrument rules do not depend on the specification of the generating processes of the exogenous disturbances in the model, they are therefore robust to misspecification in these processes. The second one, initiated by Hansen and Sargent (2003, 2007), corresponds to robust control approach to the decision problem of agents who face model uncertainty. In the sense of Hansen and Sargent, robust monetary policies are designed to perform well in worst-case scenarios. These policies arise as the equilibrium in a game between the monetary authorities and an evil agent who chooses model misspecification to make the authorities look as bad as possible. While these two approaches to robust policies appear quite distinct, Walsh (2004) has demonstrated that both approaches lead to exactly the same implicit instrument rule for the monetary authorities in a standard forward-looking new Keynesian model. ${ }^{2}$

The role of model robustness has been neglected until now in the literature on transparency. In practice, central banks (especially inflation targeting central banks) seem to

\footnotetext{
${ }^{2}$ A third approach to robustness considers what is called structured Knightian uncertainty. Here, the uncertainty is assumed to be located in one or more specific parameters of the model (Onatski and Stock, 2002; Giannoni,
} 
publish plenty of analysis on their models and policy rules robustness. ${ }^{3}$ However, they are confronted with a dilemma. A simple model may give an advantage in communication with the public, but it can be criticized for not fitting the data well.

One response to such criticism is to design more complex models that are able to better capture the behaviour of macroeconomic variables. Such models gain in realism but lose in tractability. An alternative route is to acknowledge that the simple model is a misspecified description of reality and to design policy taking this misspecification into account. In other words, the central bank does not know the true structure of the economy.

Disclosure of the knowledge about the true economic structure could significantly influence the strategic interactions between central bank and private agents. In particular, monetary policy makers might use strategically their private information in order to gain benefits in terms of output stabilization.

The robustness approaches assume that government and private agents know exactly the preference parameters, in particular the preference for robustness of the central bank, while the latter does not know exactly the true model of the economy. However, in the transparency literature, government and private agents are generally uncertain about the preferences of the central bank.

If the central bank could have incentives to not communicate its preferences associated with its inflation and output targets, why does it have then incentives to communicate its preference for model robustness? In order to answer this question, we consider in this paper simultaneously the issues of transparency and model robustness in a framework of delegation similar to that used by Walsh (2003), in assuming that the central bank doesn't know exactly the true model of the economy and can be opaque about its preference for model robustness.

2002, 2007). Another current of research studies the robustness of a monetary policy rule across competing reference models. See for example McCallum (1999), and Levin and Williams (2003).

${ }^{3}$ For example, the central banks of New Zealand, Canada and United Kingdom. 
Transparency about the central bank's preference for model robustness, following the terminology defined by Geraats (2002), can be considered as political transparency which refers to openness about policy objectives and institutional arrangements that clarify the motives of monetary policymakers. ${ }^{4}$

Models focusing on monetary policy transparency typically consider two players, the monetary authority and the private sector. Departing from this approach, some authors study the relationship between central bank transparency and institutional design (Walsh, 2003; Hughes Hallett and Weymark, 2005; Hughes Hallett and Libich, 2009). Our study is closely linked to this literature.

We assume that the true model of the economy lies in some neighbourhood of the reference model, and we analyze how monetary policy should be designed in order to work reasonably well for all models inside this neighbourhood. The robust policymaker is supposed to be unable to formulate a probability distribution over plausible models and hence designs policy for the worst possible outcome within a pre-specified set of models. Its decision problem is solved using the robust control techniques (Hansen and Sargent, 2007).

The interactions between transparency and robustness and their implication for accountability will modify the private expectations and therefore affect the government's delegation decision and the incentive of the central bank to be transparent or not about its preferences for model robustness.

The accountability issue in this paper is solved through an incentive scheme that takes the form of a quadratic contract between the government and the central bank. ${ }^{5}$ We consider the

\footnotetext{
${ }^{4}$ Geraats (2002) defines five motives for central bank transparency such as political transparency, economic transparency, procedural transparency, policy transparency and operational transparency. To simplify, we do not consider other kind of transparency motives discussed in the literature. It is to note that the economic transparency (such as publication of models) must not be confused with the transparency about the preference for model robustness (political transparency).

${ }^{5}$ We remark that the accountability issue could alternatively be addressed by the conservative central banker approach due to Rogoff (1985) and the inflation contracting approach developed in Walsh (1995). The effects of
} 
government as the principal and the central bank as the agent. The central bank is delegated to attain the inflation target defined by the government. The failure of the central bank to achieve the target is associated with an inflation targeting weight (or penalty).

Under inflation targeting, the weight placed on achieving the target is a measure of the power of the incentive structure facing the central bank. Incentive schemes that are too low powered fail to ensure accountability, while ones that are too high powered can distort policy responses to changing economic conditions.

The optimal inflation targeting weight, which plays the role of Rogoff's optimal degree of conservatism, conciliates the need for accountability with the imperfect ability to monitor the central bank. If the information about the preference for model robustness on which it bases policy is private and publicly unverifiable, monitoring will be imperfect. When monitoring is incomplete due to imperfect information or lack of transparency, it is optimal to place less weight on achieving the inflation target to avoid distorting stabilization policy.

Kilponen (2003) has also considered a delegation framework including robustness issues in the Barro-Gordon framework. Considering that the central bank is perfectly transparent, he has found that the model uncertainty implies more aggressive policy responses. His simulation result shows that the more uncertain the central bank's model is, the more conservative the central should be. While we confirm his first result, our analysis finds a closed-form solution which implies the opposite of his simulation result. This divergence may be explained by the assumption adopted by Kilponen according to which the government is equally subject to model uncertainty. ${ }^{6}$ Furthermore, we analytically consider the implications of opacity.

transparency have been examined in the framework of delegation with linear central bank contracts by Beetsma and Jensen (1998), Muscatelli (1998) and Chortareas and Miller (2003).

${ }^{6}$ While this is an interesting assumption, it would make his model non-tractable. Since Kilponen has not given a closed-form solution of the optimal inflation targeting weight, we are not able to further compare with his results. 
The present study has some strong implications for the institutional design of monetary policy which can be compared with some results obtained by Hughes Hallett and Libich (2009). They examine the relationship between explicit inflation targets, communication, and central bank independence and have shown that goal-independence is inversely related to goal transparency. In our framework, the central bank already lacks goal independence as it is delegated by the government. Our analysis implies that central bank goal independence is suboptimal because, choosing its own degree of transparency about the robustness parameter, the central bank tends to prefer, under a range of circumstances, opacity to transparency, leading to inferior macroeconomic outcomes.

In the next section, we present the basic model. In the section after, we solve the model to obtain the optimal inflation targeting weight under full transparency about the preference for robustness. The effects of opacity on inflation targeting weight, monetary policy robustness as well as the macroeconomic performance and volatility are examined in section 4 . In section 5 , we discuss the implications of a serially correlated inflation shock for macroeconomic performance, monetary policy robustness and optimal inflation targeting weight. The last section concludes.

\section{The model}

Our description of economic environment follows the standard New-Keynesian model based on optimizing private sector behaviour and nominal rigidities that has been used extensively in the recent literature on monetary policy (Clarida et al. 1999).

Instead of formulating monetary policy explicitly in terms of control over the nominal interest rate, we simplify by treating the output gap, i.e. output relative to the flexible-price equilibrium level, as the instrument of monetary policy. We could also consider that the 
central bank sets the interest rate in order to attain output and inflation targets in taking account of the goods market equilibrium condition. However, this condition is neglected, similarly to Walsh (2003), in the present paper without affecting our results.

In the following, we use only the New-Keynesian Philips curve extended to take account of model misspecifications faced by the central bank. It is completed by a description of principal-agent framework where central bank preference for robustness is not perfectly observable by the government and the public.

\subsection{The economy}

The economy is characterized by a forward-looking Phillips curve:

$$
\pi_{t}=\beta \mathrm{E}_{t} \pi_{t+1}+\delta x_{t}+e_{t}, \quad \text { with } 0<\beta<1, \delta>0 \text {, }
$$

where $\pi_{t}$ is the inflation rate, $\mathrm{E}_{t} \pi_{t+1}$ the private sector's expectation of future inflation, $x_{t}$ the output gap, $e_{t}$ a serially uncorrelated inflation or cost-push shock, and $\beta$ the discount rate. The parameter $\delta$ is the output-gap elasticity of inflation and captures the effects of the gap on real marginal costs and marginal cost on inflation.

While the central bank considers the forward-looking Phillips curve described by equation (1) as the most likely specification, it realizes that the true Phillips curve may deviate from the benchmark, although it is unable to specify a probability distribution of deviations. To model such misspecification, we introduce in equation (1) a second type of disturbance, denoted by $h_{t}$. In the sense of Hansen and Sargent (2007), the disturbance is controlled by a fictitious “evil agent” representing the policymaker’s worst fears concerning model misspecification. Thus, the forward-looking Phillips curve with misspecification is given by

$$
\pi_{t}=\beta \mathrm{E}_{t} \pi_{t+1}+\delta x_{t}+e_{t}+h_{t}
$$


The disturbance $h_{t}$ is not a shock that can be described by a law of probability distribution. Its value will depend on central bank's preference for model robustness.

The robust policy is designed to perform well for one of the least likely outcomes of the model. This model is within a pre-specified set of models, which is chosen so that the policymaker cannot statistically reject any of the models inside the set. Throughout this analysis, we focus on marginal amounts of robustness, so monetary policy is robust against very small degrees of misspecification. In the case of major misspecification, the evil agent will be able to overturn any relationship in the model. Consequently, the basic relationship in equation (2) is not a good description of reality (Leitemo and Söderström, 2008).

It is to notice that introducing the IS curve will not change the equilibrium solution. As shown by Leitemo and Söderström (2008), the central bank only worries about model misspecification in the Phillips curve since the optimal misspecification in the IS equation is always zero in the closed economy. In effect, the central bank does not fear such misspecification in the IS equation because it is able to offset any misspecification by an appropriate adjustment of the interest rate so that its loss function is not affected by these interest rate movements.

\subsection{Policy objectives with preference for robustness}

In order to study the incentive of the central bank to be more or less transparent, we distinguish between the objective functions of the principal, referred to as the government (or the public), and the agent, the central bank. The role of the government will be to design the targeting regime under which the central bank conducts policy. The central bank is delegated to attain the target defined by the government. In order to ensure the accountability of the central bank, its failure to achieve the target is associated with an inflation targeting weight (or penalty). 
The expected social loss function that the government minimizes takes the standard form:

$$
L_{t}^{S}=\frac{1}{2} E_{t} \sum_{i=0}^{\infty} \beta^{i}\left(\lambda x_{t+i}^{2}+\pi_{t+i}^{2}\right), \quad \lambda>0
$$

where $\lambda$ is the relative weight placed on the output-gap objective. Social loss depends on output gap and inflation variability.

In the model of Walsh (2003), the central bank is subject to political pressures for economic expansions, captured by allowing for random fluctuations in the central bank's output-gap target. In the present model, by eliminating this source of uncertainty about central bank preferences and hence the relating inflation bias which is not central to our investigation, we focus on the implications of a new kind of uncertainty concerning the preference for model robustness. Furthermore, discretionary policy implemented to minimize (3) would not be subject to an inflation bias due to the overly ambitious output-gap target common in the Barro-Gordon framework.

The central bank is assumed to minimize a standard objective function which is quadratic in deviations of inflation and output gap from their zero target levels. In order to design robust monetary policy, the central bank takes into account a certain degree of model misspecification by minimizing its objective function in the worst possible model within a given set of plausible models. As it is common in the robust control literature, we assume that the central bank, depending on its preference for model robustness, allocates a budget $\chi^{2}$ to the evil agent who creates misspecifications under the following budget constraint:

$$
E_{t} \sum_{j=0}^{\infty} \rho^{i} h_{t+j}^{2} \leq \chi^{2}
$$

Following Hansen and Sargent (2007), the robust monetary policy is obtained by solving the min-max problem: 


$$
\min _{x_{t+i}} \max _{h_{t+i}} L_{t}^{C B}=\frac{1}{2} E_{t} \sum_{i=0}^{\infty} \beta^{i}\left[\lambda x_{t+i}^{2}+(1+\tau) \pi_{t+i}^{2}-\theta h_{t+i}^{2}\right]
$$

subject to the misspecified New Keynesian Phillips curve described in equation (2) and the evil agent's budget constraint (4). In the loss function (5), $\tau$ is the inflation targeting weight (or penalty), which plays the role of Rogoff's degree of conservatism. $\theta$ denotes the preference for robustness which is known only to the central bank, but neither to the government nor to the private sector. It determines the set of models available to the evil agent against which the policymaker wants to be robust.

When taking their decision, the government and the private agents can make guesses about the value of $\theta$. We assume that they have constant beliefs about this parameter, that are normally distributed with mean value $\bar{\theta}$ and variance $\sigma_{\theta}^{2}$.

The last term in (5) is specific to the robust control techniques adopted by the central bank. As $\tau$ could be negative, to ensure the consistency of the loss function, we assume that

$$
1+\tau>0
$$

i.e. the deviation from inflation target constitutes always a loss.

The central bank and the evil agent play a Nash game, so their choice is optimal given the other player's choice. ${ }^{7}$ The central bank thus sets the output level to minimize the value of its intertemporal loss function, while the evil agent sets its controls to maximize the central bank’s loss, given the constraints on misspecifications.

The robustness parameter, $\theta$, is inversely related to the evil agent's budget. From inequality (4), we deduce that:

$$
h_{t} \rightarrow 0 \text {, if } \chi \rightarrow 0 \text {. }
$$

\footnotetext{
7 This is not the only possible assumption. An alternative assumption is that the central bank is a Stackelberg leader, and makes its policy choice taking into account how the evil agent will choose the specification errors (Leitemo and Söderström, 2008).
} 
In other words, as the budget shrinks towards zero, the degree of misspecification approaches zero and hence $\theta$ will approach infinity.

In the following, we define the full transparency of monetary policy as a benchmark situation where the central bank communicates the exact value of $\theta$ to the public, in other words, the variance of $\theta$ is equal to zero $\left(\sigma_{\theta}^{2}=0\right)$. When the variance of $\theta$ is greater than zero $\left(\sigma_{\theta}^{2}>0\right)$ and increases, central bank transparency decreases or alternatively central bank opacity increases. In order to simplify, we assume that $\theta$ is independent of the cost shock $e_{t}$ so that the covariance $\operatorname{cov}\left(e_{t}, \theta\right)$ is zero. ${ }^{8}$

\section{Optimal inflation targeting weight under transparent robust control}

The timing of the Stackelberg game between the government, the private sector and the central bank is as follows. First, each government sets the inflation targeting weight; second, the private sector forms its expectations about inflation; third, the central bank chooses the output gap. This game is solved by backward induction.

The central bank implements the time-consistent discretionary monetary policy which is robust to model misspecifications. The min-max program (5) becomes:

$$
\min _{x_{t}} \max _{h_{t}} L_{t}^{C B}=\frac{1}{2} E_{t}^{C B}\left[\lambda x_{t}^{2}+(1+\tau) \pi_{t}^{2}-\theta h_{t}^{2}\right]
$$

subject to identical constraints as before. Under discretion, the central bank treats expectations of future inflation as given in setting $x_{t}$ and $h_{t}$.

\footnotetext{
${ }^{8}$ This assumption is adopted for tractability reasons. An alternative assumption is that the parameter $\theta$ is correlated with the cost shock $e_{t}$. It could be justified if the preference for robustness is related to forecast errors using the basic model. One would expect a central bank to be more averse to model misspecification if the shocks are larger. This is because the consequences are potentially more severe and the central bank's loss function is quadratic.
} 
The first-order conditions for the min-max problem are:

$$
\begin{aligned}
& \frac{\partial L_{t}^{C B}}{\partial x_{t}}=0 \Rightarrow \lambda x_{t}+(1+\tau) \pi_{t} \delta=0, \\
& \frac{\partial L_{t}^{C B}}{\partial h_{t}}=0 \Rightarrow(1+\tau)\left(\delta x_{t}+e_{t}\right)+(1+\tau-\theta) h_{t}=0 .
\end{aligned}
$$

The second-order condition for the maximization program of evil agent puts a limit on the value of $\theta$ and is derived from condition (10) as follows:

$$
\frac{\partial^{2} L_{t}^{C B}}{\partial h_{t}^{2}}<0 \Rightarrow \theta>1+\tau
$$

Inequality (11) implies that $\theta$ should be at least greater than $1+\tau$ for the min-max problem of the central bank to have a solution.

Using equation (2) and (9) and (10), we obtain a difference equation of inflation rate:

$$
\mathrm{E}_{t} \pi_{t+1}=\frac{\lambda(1+\tau)-\theta\left[\lambda+(1+\tau) \delta^{2}\right]}{\beta \lambda(1+\tau-\theta)} \pi_{t}+\frac{\theta}{\beta(1+\tau-\theta)} e_{t}
$$

The only state variable in this model is the exogenous cost shock $e_{t}$. Under the rational expectations hypothesis, we solve for endogenous variables using the method of undetermined coefficients (McCallum, 1983). In accordance with this method, we guess that the solutions of $\pi_{t}$ and $E_{t} \pi_{t+1}$ take the following forms:

$$
\begin{aligned}
& \pi_{t}=\zeta e_{t}, \\
& \mathrm{E}_{t} \pi_{t+1}=\mathrm{E}_{t} \zeta e_{t+1} .
\end{aligned}
$$

Assuming that the private sector forms its rational expectations of $\mathrm{E}_{t} \pi_{t+1}$ conditional on information available at $t$, we obtain:

$$
\mathrm{E}_{t} \pi_{t+1}=0
$$

Taking account of (15), equations (9)-(10) and (12) can be solved jointly for equilibrium inflation rate, output gap and model misspecification as follows: 


$$
\begin{aligned}
& \pi_{t}=\frac{\theta \lambda}{\theta\left[\lambda+(1+\tau) \delta^{2}\right]-\lambda(1+\tau)} e_{t}, \\
& x_{t}=-\frac{\delta \theta(1+\tau)}{\theta\left[\lambda+(1+\tau) \delta^{2}\right]-\lambda(1+\tau)} e_{t} \\
& h_{t}=\frac{\lambda(1+\tau)}{\theta\left[\lambda+(1+\tau) \delta^{2}\right]-\lambda(1+\tau)} e_{t} .
\end{aligned}
$$

where $\theta\left[\lambda+(1+\tau) \delta^{2}\right]-\lambda(1+\tau)>0$ according to condition (11). The above solutions imply that current inflation rate and model misspecification positively (while output gap negatively) react to the inflation shock.

Equation (18) shows that the degree of misspecification, $h_{t}$, is negatively related to $\theta$. When $\theta \rightarrow \infty$, the central bank is certain about its economic model. In this case, solutions (16)-(18) become:

$$
\begin{aligned}
& \pi_{t}=\frac{\lambda}{\lambda+(1+\tau) \delta^{2}} e_{t}, \\
& x_{t}=-\frac{(1+\tau) \delta}{\lambda+(1+\tau) \delta^{2}} e_{t}, \\
& h_{t}=0 .
\end{aligned}
$$

The central bank is a risk-averse agent who wants to avoid particularly bad outcomes, and therefore needs policy to be robust against model misspecification that could have particularly severe consequences. Unambiguously, its preference for model robustness will affect the outcomes of macroeconomic variables.

The equilibrium solutions of inflation rate, output gap and model misspecification react to the stochastic and unverifiable realization of inflation shocks. Central bank accountability modifies the effects of these shocks on endogenous variables as follows:

$$
\frac{\partial^{2} \pi_{t}}{\partial e_{t} \partial \tau}=\frac{\theta \lambda\left(\lambda-\theta \delta^{2}\right)}{\left\{\theta\left[\lambda+(1+\tau) \delta^{2}\right]-\lambda(1+\tau)\right\}^{2}}<0, \text { if } \lambda-\theta \delta^{2}<0,
$$




$$
\begin{gathered}
\frac{\partial^{2} x_{t}}{\partial e_{t} \partial \tau}=-\frac{\theta^{2} \delta \lambda}{\left\{\theta\left[\lambda+(1+\tau) \delta^{2}\right]-\lambda(1+\tau)\right\}^{2}}<0, \\
\frac{\partial^{2} h_{t}}{\partial e_{t} \partial \tau}=\frac{\lambda^{2} \theta}{\left\{\theta\left[\lambda+(1+\tau) \delta^{2}\right]-\lambda(1+\tau)\right\}^{2}}>0 .
\end{gathered}
$$

The effect of $e_{t}$ on inflation is decreasing in $\tau$ if the parameter $\theta$ is large enough to ensure that $\lambda-\theta \delta^{2}<0$. The effects of $e_{t}$ on output gap and model misspecification are decreasing and increasing respectively in $\tau$.

For given $\tau$, the effects of $e_{t}$ on these variables also depend on $\theta$ as shown by the following derivatives:

$$
\begin{aligned}
\frac{\partial^{2} \pi_{t}}{\partial e_{t} \partial \theta} & =\frac{-\lambda^{2}(1+\tau)}{\left\{\theta\left[\lambda+(1+\tau) \delta^{2}\right]-\lambda(1+\tau)\right\}^{2}}<0, \quad \text { if } \lambda-\theta \delta^{2}<0 \\
\frac{\partial^{2} x_{t}}{\partial e_{t} \partial \theta} & =\frac{(1+\tau)^{2} \delta \lambda}{\left\{\theta\left[\lambda+(1+\tau) \delta^{2}\right]-\lambda(1+\tau)\right\}^{2}}>0, \\
\frac{\partial^{2} h_{t}}{\partial e_{t} \partial \theta} & =\frac{-\lambda(1+\tau)\left[\lambda+(1+\tau) \delta^{2}\right]}{\left\{\theta\left[\lambda+(1+\tau) \delta^{2}\right]-\lambda(1+\tau)\right\}^{2}}<0
\end{aligned}
$$

The effect of $e_{t}$ on inflation rate is decreasing in $\theta$. This means that if the central bank has a lower preference for model robustness (higher $\theta$ ), it is less aggressive in response to inflation shocks. ${ }^{9}$ The effects of $e_{t}$ on output-gap and model misspecification are increasing and decreasing respectively in $\theta$.

The government faces the trade-off between the need for accountability and the need for stabilization given that the central bank uses the robust control approach in implementing the targeting regime. The optimal inflation targeting weight is obtained by minimizing the social loss function (3) with respect to $\tau$, taking account of equations (16)-(17). The first-order condition of the government minimization problem is:

\footnotetext{
${ }^{9}$ See also Leitemo and Söderström (2008).
} 


$$
\frac{\partial L_{t}^{S}}{\partial \tau}=0 \Rightarrow E_{t}\left(\lambda x_{t} \frac{\partial x_{t}}{\partial \tau}+\pi_{t} \frac{\partial \pi_{t}}{\partial \tau}\right)=0
$$

Deriving $\pi_{t}$ and $x_{t}$ given by (16) and (17) with respect to $\tau$ and substituting the resulting derivatives as well as $\pi_{t}$ and $x_{t}$ given by (16) and (17) into the first-order condition (28), we obtain:

$$
E_{t}\left[\frac{\left(\tau \theta \delta^{2}+\lambda\right) \lambda^{2} \theta^{2}\left(e_{t}\right)^{2}}{\left\{\theta\left[\lambda+(1+\tau) \delta^{2}\right]-\lambda(1+\tau)\right\}^{3}}\right]=0
$$

If $\theta$ is known with certainty, solving equation (29) gives the solution of $\tau$ as follows:

$$
\tau=\frac{-\lambda}{\theta \delta^{2}}<0
$$

The optimal solution of penalty implies that condition (6), i.e. $1+\tau>0$, is equivalent to the condition $\lambda-\theta \delta^{2}<0$ that is used to obtain the result reported in (22). In the case where $\theta \rightarrow \infty$, i.e. absence of robust control, we have $\lim _{\theta \rightarrow \infty} \tau=0 .{ }^{10}$ It follows from (30) that $\frac{d \tau}{d \theta}=\frac{\lambda}{\theta^{2} \delta^{2}}>0$. These results are summarized in the following proposition.

Proposition 1. When the central bank's preference for model robustness is known with certainty $\left(\sigma_{\theta}^{2}=0\right)$ by the government and the public, the optimal inflation targeting weight $\tau$ is negative and decreasing with the preference for model robustness.

We remark that in the case of full transparency $\left(\sigma_{\theta}^{2}=0\right)$ and in the absence of robust control (i.e. $\theta \rightarrow \infty$ ), it is not necessary to impose any penalty since $\lim _{\theta \rightarrow \infty} \tau=0$. According to

\footnotetext{
${ }^{10}$ Following Walsh (2003), we can introduce in the loss function of the central bank, a parameter $u_{t}$, i.e. the mean zero period $t$ realization of the net pressures for economic expansion. The realization of $u_{t}$ is known by the central bank, although it is assumed to be unverifiable private information. Therefore, the optimal penalty
} 
equation (25), when the central bank implements robust control approach ( $\theta$ decreases), the inflation rate increases and this implies higher social loss.

Under model uncertainty, an increase in the penalty induced by a reduction of $\theta$ will not necessarily attain the goal of reducing the inflation rate, since it has a double effect on inflation rate.

Higher penalty incites the central bank to reduce the responses of inflation rate to inflation shock (direct effect) in favour of increased model misspecification, leading to higher inflation (indirect effect). Furthermore, a higher preference for model robustness (lower $\theta$ ) has also a positive effect on model misspecification, leading to higher inflation.

In our analysis, the negative direct effect of a higher penalty on inflation is dominated by its indirect effect and the effect of higher preference for model robustness on model misspecifications. Consequently, the government will counterbalance the inflationary effect of higher preference for model robustness by decreasing the inflation targeting weight.

In other words, our results imply that the government should appoint a liberal central banker, which is the opposite of the finding of Rogoff (1985). More uncertain the central bank is about its model, less weight the central bank should assign on inflation under optimal delegation.

\section{The effects of opacity about the preference for model robustness}

The results summarized in Proposition 1 are obtained under the assumption that information about the preference for model robustness is transmitted to the government and private agents. In the following, we relax this assumption in admitting that this information is

will be $\tau=\left[\left(\lambda \theta \delta^{2}-2 \lambda \delta^{2}+\theta \delta^{4}\right) \sigma_{u}^{2}-\lambda \sigma_{e}^{2}\right] /\left(\lambda \delta^{2} \sigma_{u}^{2}+\theta \delta^{2} \sigma_{e}^{2}\right)$ with $\partial \tau / \partial \theta>0$ and $\partial \tau / \partial \sigma_{u}^{2}>0$. The result is reduced to that of Walsh if $\theta \rightarrow \infty$ (i.e., in the absence of model misspecification): $\lim _{\theta \rightarrow \infty} \tau=\left(\lambda+\delta^{2}\right) \sigma_{u}^{2} / \sigma_{e}^{2}$. 
private to the central bank. We then investigate whether the lack of transparency about the preference for model robustness can be used strategically by the central bank in order to reduce the penalty inflicted by the government. For this purpose, we will study the effects of opacity on the level and variability of inflation, output gap and model misspecification.

\subsection{Effects of opacity on the macroeconomic performance}

Substituting the solution of $\pi_{t}$ and $x_{t}$ given by equations (16) and (17) into expected social loss function (3) leads to

$$
\begin{aligned}
L_{t}^{S} & =\frac{1}{2} E_{t}\left\{\lambda\left[\frac{-\theta(1+\tau) \delta e_{t}}{\theta\left[\lambda+(1+\tau) \delta^{2}\right]-\lambda(1+\tau)}\right]^{2}+\left[\frac{\theta \lambda e_{t}}{\theta\left[\lambda+(1+\tau) \delta^{2}\right]-\lambda(1+\tau)}\right]^{2}\right\} \\
& =\frac{1}{2} E_{t}\left\{\frac{\left[\lambda \theta^{2} \delta^{2}(1+\tau)^{2}+\theta^{2} \lambda^{2}\right]\left(e_{t}\right)^{2}}{\left\{\theta\left[\lambda+(1+\tau) \delta^{2}\right]-\lambda(1+\tau)\right\}^{2}}\right\} .
\end{aligned}
$$

The application of second-order Taylor approximation to the expected social loss function (31) yields

$$
L^{S}=\frac{1}{2} \frac{\left[\lambda \bar{\theta}^{2} \delta^{2}(1+\tau)^{2}+\bar{\theta}^{2} \lambda^{2}\right] \sigma_{e}^{2}}{\left\{\theta\left[\lambda+(1+\tau) \delta^{2}\right]-\lambda(1+\tau)\right\}^{2}}+\frac{\Omega}{2} \sigma_{\theta}^{2} .
$$

with $\Omega=\frac{\left[\delta^{2}(1+\tau)^{2}+\lambda\right]\left\{(1+\tau)^{2} \lambda^{3}+2(1+\tau) \bar{\theta} \lambda^{2}\left[(1+\tau) \delta^{2}+\lambda\right]\right\} \sigma_{e}^{2}}{\left\{\bar{\theta}\left[\lambda+(1+\tau) \delta^{2}\right]-\lambda(1+\tau)\right\}^{4}}$.

Proposition 2: For given $\tau$, an increase in opacity deteriorates the social welfare in the case of serially uncorrelated inflation shocks.

Proof: Using equation (32), deriving the social loss with regard to the degree of opacity leads to : $\frac{\partial L^{S}}{\partial \sigma_{\theta}^{2}}=\frac{\Omega}{2}>0$ for $\sigma_{e}^{2}>0$. Q.E.D. 
By increasing the robustness of monetary policy (decreasing $\theta$ ), the central bank can induce an increase in the optimal inflation targeting weight and hence its goal independence. Opacity about the preference for robustness can further increase (or not, depending on the initial conditions) its independence vis-à-vis the government. However, an increase in opacity is suboptimal from the point of view of government since it implies a higher social loss. In effect, for any given inflation targeting weight, opacity induces a higher volatility of inflation and output gap (see equations (31)-(32)). The government may be induced to decrease the inflation targeting weight in order to favour a reduction in model robustness.

Proposition 3: Starting from the initial equilibrium characterized by full transparency $\left(\sigma_{\theta}^{2}=0\right)$, an increase in opacity about the preference for model robustness will incite the government to decrease the optimal inflation targeting weight (i.e. $\frac{d \tau}{d \sigma_{\theta}^{2}}<0, \forall \bar{\theta}>\frac{\lambda}{\delta^{2}}$ ), and will increase (reduce) the sensibility of inflation and model misspecification (output gap respectively) to the inflation shock.

Proof: See Appendix A for demonstration of $\frac{d \tau}{d \sigma_{\theta}^{2}}<0, \forall \bar{\theta}>\frac{\lambda}{\delta^{2}}$ when $\sigma_{\theta}^{2}=0$. Given that $\frac{d \tau}{d \sigma_{\theta}^{2}}<0$, the effects of opacity on the sensibility of $\pi_{t}, x_{t}$ and $h_{t}$ can be shown by deriving equations (16)-(18) with respect to $\sigma_{\theta}^{2}$ as follows:

$$
\begin{array}{ll}
\frac{\partial^{2} \pi_{t}}{\partial e_{t} \partial \sigma_{\theta}^{2}}=\frac{\theta \lambda\left(\lambda-\theta \delta^{2}\right)}{\left\{\theta\left[\lambda+(1+\tau) \delta^{2}\right]-\lambda(1+\tau)\right\}^{2}} \frac{\partial \tau}{\partial \sigma_{\theta}^{2}}>0, \quad \text { since } \lambda-\theta \delta^{2}<0 ; \\
\frac{\partial^{2} x_{t}}{\partial e_{t} \partial \sigma_{\theta}^{2}}=\frac{-\theta^{2} \delta \lambda}{\left\{\theta\left[\lambda+(1+\tau) \delta^{2}\right]-\lambda(1+\tau)\right\}^{2}} \frac{\partial \tau}{\partial \sigma_{\theta}^{2}}>0, \\
\frac{\partial^{2} h_{t}}{\partial e_{t} \partial \sigma_{\theta}^{2}}=\frac{\theta \lambda}{\left\{\theta\left[\lambda+(1+\tau) \delta^{2}\right]-\lambda(1+\tau)\right\}^{2}} \frac{\lambda \partial \tau}{\partial \sigma_{\theta}^{2}}>0 . & \text { Q.E.D. }
\end{array}
$$


Given the optimal solution of $\tau$, i.e. equation (30), condition (6) is equivalent to assuming that $\lambda-\theta \delta^{2}<0$ or $\theta>\frac{\lambda}{\delta^{2}}$. The results concerning the sensibility of $\pi_{t}, x_{t}$ and $h_{t}$ to the inflation shock are closely linked to the negative effect of opacity on the inflation targeting weight decided by the government.

If the central bank is opaque about its preference for model robustness, the resulting uncertainty increases the social loss as shown by Proposition 2 and therefore affects the government's decision on the optimal inflation targeting weight. The optimal solution for the government is to reduce the penalty in order to counterbalance the negative effect of opacity on social welfare. In other words, if an increase in the preference for robustness is equivalent to gaining more independence for the central bank, the latter can increase further its independence by being opaque.

Without opacity, the inflation shock positively affects the inflation rate and model misspecification but has a negative effect on the output gap. Hence, $\frac{\partial^{2} \pi_{t}}{\partial e_{t} \partial \sigma_{\theta}^{2}}>0$ and $\frac{\partial^{2} h_{t}}{\partial e_{t} \partial \sigma_{\theta}^{2}}>0$ imply that opacity reinforces the sensibility of inflation and model misspecification to the inflation shock and $\frac{\partial^{2} x_{t}}{\partial e_{t} \partial \sigma_{\theta}^{2}}>0$ implies that the sensibility of output gap to the inflation shock is reduced.

\subsection{Effects of opacity on the macroeconomic volatility}

To study how opacity affects the volatility of $\pi_{t}, x_{t}$ and $h_{t}$, we calculate their variance by taking $\tau$ as independent of the realisation of $\theta$, i.e. their correlation is zero. In effect, $\tau$ depends only on the expected value and variance of $\theta$.

Using equations (16)-(18) and the second-order Taylor approximation, we obtain:

$$
\operatorname{var}\left(\pi_{t}\right)=\left\{\bar{\theta}^{2} \bar{\Theta}^{-2}+\left\{2 \bar{\theta} \lambda(1+\tau)\left[\lambda+(1+\tau) \delta^{2}\right]+\lambda^{2}(1+\tau)^{2}\right\} \bar{\Theta}^{-4} \sigma_{\theta}^{2}\right\} \lambda^{2} \sigma_{e}^{2},
$$




$$
\begin{aligned}
& \operatorname{var}\left(x_{t}\right)=\left\{\bar{\theta}^{2} \bar{\Theta}^{-2}+\left\{2 \bar{\theta} \lambda(1+\tau)\left[\lambda+(1+\tau) \delta^{2}\right]+\lambda^{2}(1+\tau)^{2}\right\} \bar{\Theta}^{-4} \sigma_{\theta}^{2}\right\}[(1+\tau) \delta]^{2} \sigma_{e}^{2}, \\
& \operatorname{var}\left(h_{t}\right)=\left\{\bar{\Theta}^{-2}+3\left[\lambda+(1+\tau) \delta^{2}\right]^{2} \bar{\Theta}^{-4} \sigma_{\theta}^{2}\right\}[\lambda(1+\tau)]^{2} \sigma_{e}^{2},
\end{aligned}
$$

where $\bar{\Theta}=\bar{\theta}\left[\lambda+(1+\tau) \delta^{2}\right]-\lambda(1+\tau)$.

The volatility of $\pi_{t}, x_{t}$ and $h_{t}$ is generated by the inflation shock. Opacity influences the volatility of these variables through the preference for model robustness and through its effect on the government's decision about the inflation targeting weight.

Denote $\quad$ that: $\quad \Omega=-\frac{2 \bar{\theta} \lambda(1+\tau)\left[\lambda+(1+\tau) \delta^{2}\right]+\lambda^{2}(1+\tau)^{2} \bar{\Theta}}{-2 \bar{\theta}^{2}\left(\bar{\theta} \delta^{2}-\lambda\right) \bar{\Theta}^{2}+\left\{\left(\lambda-2 \bar{\theta} \delta^{2}\right) \lambda \bar{\theta} \delta^{2}(1+\tau)^{2}+6 \lambda^{3} \bar{\theta}(1+\tau)+\lambda^{3}(1+\tau)^{2}+2 \bar{\theta}^{2} \lambda^{3}\right\} \sigma_{\theta}^{2}} \quad$ and $\Phi=\frac{2 \bar{\theta}^{2}\left(\bar{\theta} \delta^{2}-\lambda\right) \bar{\Theta}^{2}}{\left(\lambda-2 \bar{\theta} \delta^{2}\right) \lambda \bar{\theta} \delta^{2}(1+\tau)^{2}+6 \lambda^{3} \bar{\theta}(1+\tau)+\lambda^{3}(1+\tau)^{2}+2 \bar{\theta}^{2} \lambda^{3}} \cdot{ }^{11}$ The effects of opacity on macroeconomic volatility are summarized in the following proposition.

Proposition 4a: i) More opacity reinforces the volatility of inflation if $\Phi<0$ or if $\Omega<\frac{d \tau}{d \sigma_{\theta}^{2}}$ and $\sigma_{\theta}^{2}>\Phi>0$; ii) More opacity reduces the volatility of inflation if $\frac{d \tau}{d \sigma_{\theta}^{2}}<\Omega$ and $\sigma_{\theta}^{2}>\Phi>0$

Proof: Deriving $\operatorname{var}\left(\pi_{t}\right)$ given by equation (33) with respect to $\sigma_{\theta}^{2}$ yields: $\frac{\partial \operatorname{var}\left(\pi_{t}\right)}{\partial \sigma_{\theta}^{2}}=\left[\begin{array}{l}-2 \bar{\theta}^{2}\left(\bar{\theta} \delta^{2}-\lambda\right) \bar{\Theta}^{-3} \frac{d \tau}{d \sigma_{\theta}^{2}}+\left\{2 \bar{\theta} \lambda(1+\tau)\left[\lambda+(1+\tau) \delta^{2}\right]+\lambda^{2}(1+\tau)^{2}\right\} \bar{\Theta}^{-4} \\ +\left\{\left(\lambda-2 \bar{\theta} \delta^{2}\right) \lambda \bar{\theta} \delta^{2}(1+\tau)^{2}+6 \lambda^{3} \bar{\theta}(1+\tau)+\lambda^{3}(1+\tau)^{2}+2 \bar{\theta}^{2} \lambda^{3}\right\} \bar{\Theta}^{-5} \sigma_{\theta}^{2} \frac{d \tau}{d \sigma_{\theta}^{2}}\end{array}\right] \lambda^{2} \sigma_{e}^{2}$

Solving for $\frac{\partial \operatorname{var}\left(\pi_{t}\right)}{\partial \sigma_{\theta}^{2}}>0$ and $\frac{\partial \operatorname{var}\left(\pi_{t}\right)}{\partial \sigma_{\theta}^{2}}<0$ respectively leads to conditions given in Proposition 4a. Q.E.D.

\footnotetext{
${ }^{11}$ It is easy to show that $\Phi>0$ if $\left[1+\frac{\lambda}{\bar{\theta} \delta^{2}}+\frac{6 \lambda}{\delta^{2}(1+\tau)}+\frac{2 \bar{\theta} \lambda}{\delta^{2}(1+\tau)^{2}}\right] \frac{\lambda}{\bar{\theta} \delta^{2}}>2$ and vice versa.
} 
Proposition 4b: i) More opacity reinforces the volatility of output gap if $\frac{d \tau}{d \sigma_{\theta}^{2}}>-\frac{\delta \bar{\Theta}(1+\tau)\left\{2 \bar{\theta} \lambda(1+\tau)\left[\lambda+(1+\tau) \delta^{2}\right]+\lambda^{2}(1+\tau)^{2}\right\}}{2 \delta \lambda \bar{\theta}^{3} \bar{\Theta}^{2}+\left\{\left(2 \bar{\theta} \delta^{2}-\lambda\right) \delta^{3} \bar{\theta} \lambda(1+\tau)^{3}+[2 \bar{\theta}-(1+\tau)] \delta \lambda^{3}(1+\tau)^{2}+8 \delta^{3} \lambda^{2} \bar{\theta}^{2}(1+\tau)^{2}+6 \delta \lambda^{3} \bar{\theta}^{2}(1+\tau)+2 \delta \lambda^{3} \bar{\theta}(1+\tau)^{2}\right\} \sigma_{\theta}^{2}}$.

ii) More opacity reduces the volatility of output gap if the above condition is reversed.

Proof: Deriving $\operatorname{var}\left(x_{t}\right)$ with respect to $\sigma_{\theta}^{2}$ leads to:

$$
\begin{aligned}
\frac{\partial \operatorname{var}\left(x_{t}\right)}{\partial \sigma_{\theta}^{2}}= & {\left[\begin{array}{l}
-2 \bar{\theta}^{2}\left(\bar{\theta} \delta^{2}-\lambda\right) \bar{\Theta}^{-3} \frac{d \tau}{d \sigma_{\theta}^{2}}+\left\{2 \bar{\theta} \lambda(1+\tau)\left[\lambda+(1+\tau) \delta^{2}\right]+\lambda^{2}(1+\tau)^{2}\right\} \bar{\Theta}^{-4} \\
+\left\{\left(\lambda-2 \bar{\theta} \delta^{2}\right) \lambda \bar{\theta} \delta^{2}(1+\tau)^{2}+6 \lambda^{3} \bar{\theta}(1+\tau)+\lambda^{3}(1+\tau)^{2}+2 \bar{\theta}^{2} \lambda^{3}\right\} \bar{\Theta}^{-5} \sigma_{\theta}^{2} \frac{d \tau}{d \sigma_{\theta}^{2}}
\end{array}\right][(1+\tau) \delta]^{2} \sigma_{e}^{2} } \\
& +2(1+\tau) \delta^{2}\left\{\bar{\theta}^{2} \bar{\Theta}^{-2}+\left\{2 \bar{\theta} \lambda(1+\tau)\left[\lambda+(1+\tau) \delta^{2}\right]+\lambda^{2}(1+\tau)^{2}\right\} \bar{\Theta}^{-4} \sigma_{\theta}^{2}\right\} \sigma_{e}^{2} \frac{d \tau}{d \sigma_{\theta}^{2}}
\end{aligned}
$$

Solving for $\frac{\partial \operatorname{var}\left(x_{t}\right)}{\partial \sigma_{\theta}^{2}}>0$ and $\frac{\partial \operatorname{var}\left(x_{t}\right)}{\partial \sigma_{\theta}^{2}}<0$ respectively leads to conditions given in Proposition 4b. Q.E.D.

Proposition 4c: i) More opacity reinforces the volatility of model misspecification if

$$
\frac{d \tau}{d \sigma_{\theta}^{2}}>-\frac{3 \lambda \bar{\Theta}(1+\tau)\left[\lambda+(1+\tau) \delta^{2}\right]^{2}}{2 \lambda^{2} \bar{\theta}^{2}+3\left\{\left(\delta^{2} \bar{\theta}-\lambda\right)\left[\lambda^{2}(1+\tau)+3 \lambda \delta^{2}(1+\tau)^{2}\right]+2 \bar{\theta} \lambda\left[\lambda^{2}+\lambda+\delta^{2}(1+\tau)\right]\right\}\left[\lambda+(1+\tau) \delta^{2}\right] \sigma_{\theta}^{2}} .
$$

ii) More opacity reduces the volatility of model misspecification if the above condition is reversed.

Proof: Deriving $\operatorname{var}\left(h_{t}\right)$ with respect to $\sigma_{\theta}^{2}$ yields:

$$
\begin{aligned}
& \frac{\partial \operatorname{var}\left(h_{t}\right)}{\partial \sigma_{\theta}^{2}}=3\left[\lambda+(1+\tau) \delta^{2}\right]^{2} \bar{\Theta}^{-4}[\lambda(1+\tau)]^{2} \sigma_{e}^{2}+\lambda(1+\tau) \times \\
& \left\{2 \bar{\theta} \lambda^{2} \bar{\Theta}^{-3}+\left[3\left\{\left(\delta^{2} \bar{\theta}-\lambda\right)\left[\lambda^{2}(1+\tau)+3 \lambda \delta^{2}(1+\tau)^{2}\right]+2 \bar{\theta} \lambda\left[\lambda^{2}+\lambda+\delta^{2}(1+\tau)\right]\right\}\left[\lambda+(1+\tau) \delta^{2}\right]\right] \bar{\Theta}^{-5} \sigma_{\theta}^{2}\right\} \sigma_{e}^{2} \frac{d \tau}{d \sigma_{\theta}^{2}} .
\end{aligned}
$$


Solving for $\frac{\partial \operatorname{var}\left(h_{t}\right)}{\partial \sigma_{\theta}^{2}}>0$ and $\frac{\partial \operatorname{var}\left(h_{t}\right)}{\partial \sigma_{\theta}^{2}}<0$ respectively leads to conditions given in Proposition 4c. $\quad$ Q.E.D.

The results reported in Proposition 4 suggest that generally, if the inflation targeting weight does not respond too negatively to an increase in opacity, then the variance of inflation rate, output gap and model misspecification increases and vice versa.

Having shown how opacity affects the level and volatility of economic variables, we can examine if there is a case for more opacity. When the central bank decided not to reveal private information about its preference for robustness, it accepted lower equilibrium inflation (and higher output gap) in exchange of greater macroeconomic instability. If the equilibrium level of inflation (and output gap) was increasing (and decreasing respectively) in opacity, there would be no such trade-off between the equilibrium level and volatility of inflation (and output gap) with respect to the degree of opacity. In the case where both inflation level and variability were increasing in opacity, the most desirable situation is that the central bank should be fully transparent $\left(\sigma_{\theta}^{2}=0\right)$. Inversely, if both inflation and macroeconomic variability were decreasing in opacity, there would be a case for monetary policy opacity.

According to Proposition 3, we have $\frac{\partial^{2} \pi_{t}}{\partial e_{t} \partial \sigma_{\theta}^{2}}>0$ if $\frac{d \tau}{d \sigma_{\theta}^{2}}<0$. Meanwhile, as shown by the part ii) of Proposition 4a, we have $\frac{\partial^{2} \operatorname{var}(\pi)}{\partial \sigma_{\theta}^{2}}<0$ if $\frac{d \tau}{d \sigma_{\theta}^{2}}<\Omega$ and $\sigma_{\theta}^{2}>\Phi>0$. For certain degrees of robustness and opacity, we could simultaneously have $\frac{\partial^{2} \pi_{t}}{\partial e_{t} \partial \sigma_{\theta}^{2}}>0$ and $\frac{\partial^{2} \operatorname{var}(\pi)}{\partial \sigma_{\theta}^{2}}<0$. In this case, the trade-off is possible since the central bank that desires to reduce the inflation variability could accept an increase in the sensibility of inflation to the inflation shock. 
On the other hand, the part i) of Proposition 4a) implies that $\frac{\partial^{2} \operatorname{var}(\pi)}{\partial \sigma_{\theta}^{2}}>0$ if if $\Phi<0$ or if $\Omega<\frac{d \tau}{d \sigma_{\theta}^{2}}$ and $\sigma_{\theta}^{2}>\Phi>0$. For certain expected degree of robustness and initial level of opacity, we can simultaneously have $\frac{\partial^{2} \pi_{t}}{\partial e_{t} \partial \sigma_{\theta}^{2}}>0$ and $\frac{\partial^{2} \operatorname{var}(\pi)}{\partial \sigma_{\theta}^{2}}>0$. In this case, more transparency is preferable to opacity if initially the central bank is not perfectly transparent.

\section{Implications of a serially correlated inflation shock}

Our previous results are obtained under the assumption that the inflation shock is serially uncorrelated. In this section, we relax this assumption by assuming that the inflation shock is serially correlated and follows an AR(1) process:

$$
e_{t}=\rho e_{t-1}+\varepsilon_{t}, \quad 0 \leq \rho \leq 1 \text { and } E_{t-1} \varepsilon_{t}=0 \text {; }
$$

where $\varepsilon_{t}$ has mean zero and is serially uncorrelated.

Using equations (14) and (36), we obtain:

$$
\mathrm{E}_{t} \pi_{t+1}=\mathrm{E}_{t} \zeta \rho e_{t}
$$

Substituting $\mathrm{E}_{t} \pi_{t+1}$ given by equation (37) into equation (12) leads to:

$$
\pi_{t}=\frac{-\beta \lambda(1+\tau-\theta)}{\theta\left[\lambda+(1+\tau) \delta^{2}\right]-\lambda(1+\tau)} \mathrm{E}_{t} \zeta \rho e_{t}+\frac{\lambda \theta}{\theta\left[\lambda+(1+\tau) \delta^{2}\right]-\lambda(1+\tau)} e_{t}
$$

Comparing the solution of $\pi_{t}$ given by (38) with that given by (13) yields:

$$
\zeta=\frac{-\beta \lambda(1+\tau-\theta)}{\theta\left[\lambda+(1+\tau) \delta^{2}\right]-\lambda(1+\tau)} \mathrm{E}_{t} \zeta \rho+\frac{\lambda \theta}{\theta\left[\lambda+(1+\tau) \delta^{2}\right]-\lambda(1+\tau)}
$$

In the following, we will firstly discuss some implications of the introduction of a serially correlated inflation shock on the decision of inflation targeting weight in the benchmark case of full transparency. We will then examine, under opacity, how the persistence of inflation 
shocks affects the sensibility of inflation, output gap and model misspecification to the current inflation shock. Since a closed-form solution of inflation targeting weight is not feasible, we are limited to discussing the likely impacts of the persistence of inflation shocks on the inflation targeting weight through its effect on the social loss function of the government.

\subsection{Full transparency}

Under full transparency, i.e. $\mathrm{E}_{t} \zeta=\zeta$, solving equation (39) leads to:

$$
\zeta=\frac{\lambda \theta}{\lambda(1+\tau-\theta)(\beta \rho-1)+(1+\tau) \theta \delta^{2}},
$$

where the denominator is positive since $\beta \rho-1<0$ and $1+\tau-\theta<0$.

Substituting $\zeta$ given by equation (40) into equation (13), we get:

$$
\pi_{t}=\frac{\lambda \theta}{\lambda(1+\tau-\theta)(\beta \rho-1)+(1+\tau) \theta \delta^{2}} e_{t}
$$

Using the solution of $\pi_{t}$ given by equation (41) in equation (9) to obtain the solution of $x_{t}$ and inserting the latter into equation (10) to obtain $h_{t}$ yield:

$$
\begin{aligned}
& x_{t}=-\frac{\theta \delta(1+\tau)}{\lambda(1+\tau-\theta)(\beta \rho-1)+(1+\tau) \theta \delta^{2}} e_{t}, \\
& h_{t}=\frac{\lambda(1-\beta \rho)(1+\tau)}{\lambda(1+\tau-\theta)(\beta \rho-1)+(1+\tau) \theta \delta^{2}} e_{t},
\end{aligned}
$$

By comparing equations (41)-(43) with their corresponding equations (16)-(18), we can easily find how, for given $\tau$, the introduction of a serially correlated inflation shock modifies the sensibility of endogenous variables to the inflation shock. 
Proposition 5: For given $\tau$, the introduction of a serially correlated inflation shock implies a stronger response of current inflation and output gap to the inflation shock. However, it implies a weaker response of model misspecification to the inflation shock.

Proof: Deriving $\pi_{t}, x_{t}$ and $h_{t}$ given respectively by (41), (42) and (43) with respect to $\rho$ yields:

$$
\begin{aligned}
& \frac{\partial^{2} \pi_{t}}{\partial e_{t} \partial \rho}=\frac{-\beta \lambda^{2} \theta(1+\tau-\theta)}{\left[\lambda(1+\tau-\theta)(\beta \rho-1)+(1+\tau) \theta \delta^{2}\right]^{2}}>0, \\
& \frac{\partial^{2} x_{t}}{\partial e_{t} \partial \rho}=\frac{\beta \delta \lambda \theta(1+\tau)(1+\tau-\theta)}{\left[\lambda(1+\tau-\theta)(\beta \rho-1)+(1+\tau) \theta \delta^{2}\right]^{2}}<0, \\
& \frac{\partial^{2} h_{t}}{\partial e_{t} \partial \rho}=\frac{-\lambda \beta(1+\tau)^{2} \theta \delta^{2}}{\left[\lambda(1+\tau-\theta)(\beta \rho-1)+(1+\tau) \theta \delta^{2}\right]^{2}}<0 .
\end{aligned}
$$

According to equations (16)-(18), in the absence of a serially correlated inflation shock, inflation and model misspecification positively react to the inflation shock while output gap negatively reacts to it. Comparing these results with these given by equations (44), (45) and (46) leads to Proposition 5. Q.E.D.

Deriving $\pi_{t}$ and $x_{t}$ given by (41) and (42) with respect to $\tau$ and substituting the resulting derivatives as well as $\pi_{t}$ and $x_{t}$ given by (41) and (42) into the first-order condition (28), we obtain:

$$
\tau=-\frac{\lambda}{\theta \delta^{2}}+\frac{\beta \rho}{1-\beta \rho}
$$

The difference between the solution of $\tau$ given by (47) and that given by (30) is equal to $\frac{\beta \rho}{1-\beta \rho}$. Since $1-\beta \rho>0$, it follows that the optimal inflation targeting weight is higher in the case of a serially correlated inflation shock. 
Proposition 6: The optimal inflation targeting weight increases with the degree of persistence of inflation shocks.

Proof: Deriving the solution of $\tau$ given by equation (47) leads straightforwardly to $\frac{\partial \tau}{\partial \rho}=\frac{\beta}{(1-\beta \rho)^{2}}>0$ Q.E.D.

An increase in the persistence of inflation shocks will induce the government to increase the inflation targeting weight. Consequently, the central bank should assign a higher weight on inflation under optimal delegation.

\subsection{Opacity}

Under opacity, taking expectations of equation (39) and applying to the resulting equation the second-order Taylor approximation under the assumption of opacity, we obtain: ${ }^{12}$

$$
\mathrm{E}_{t} \zeta=\frac{\bar{\theta} \lambda \bar{\Theta}^{2}+\lambda^{2}(1+\tau)\left[(1+\tau) \delta^{2}+\lambda\right] \sigma_{\theta}^{2}}{\left[\lambda(1+\tau-\bar{\theta})(\beta \rho-1)+\bar{\theta}(1+\tau) \delta^{2}\right] \bar{\Theta}^{2}+(1+\tau)^{2}\left[(1+\tau) \delta^{2}+\lambda\right] \beta \delta^{2} \lambda \rho \sigma_{\theta}^{2}}
$$

Substituting $\mathrm{E}_{t} \zeta$ given by equation (48) into equations (37) and (38) respectively yields:

$$
\begin{aligned}
& \mathrm{E}_{t} \pi_{t+1}=\frac{\bar{\theta} \lambda \bar{\Theta}^{2}+\lambda^{2}(1+\tau)\left[(1+\tau) \delta^{2}+\lambda\right] \sigma_{\theta}^{2}}{\left[\lambda(1+\tau-\bar{\theta})(\beta \rho-1)+\bar{\theta}(1+\tau) \delta^{2}\right] \bar{\Theta}^{2}+(1+\tau)^{2}\left[(1+\tau) \delta^{2}+\lambda\right] \beta \delta^{2} \lambda \rho \sigma_{\theta}^{2}} \rho e_{t}, \\
& \pi_{t}=\frac{-\lambda}{\theta\left[\lambda+(1+\tau) \delta^{2}\right]-\lambda(1+\tau)}\left[\frac{\beta(1+\tau-\theta)\left\{\bar{\theta} \lambda \bar{\Theta}^{2}+\lambda^{2}(1+\tau)\left[(1+\tau) \delta^{2}+\lambda\right] \sigma_{\theta}^{2}\right\} \rho}{\left[\lambda(1+\tau-\bar{\theta})(\beta \rho-1)+\bar{\theta}(1+\tau) \delta^{2}\right] \bar{\Theta}^{2}+(1+\tau)^{2}\left[(1+\tau) \delta^{2}+\lambda\right] \beta \delta^{2} \lambda \rho \sigma_{\theta}^{2}}-\theta\right] e_{t} .
\end{aligned}
$$

Using the solution of $\pi_{t}$ given by equation (50) in equation (9) to obtain $x_{t}$ and inserting the latter in equation (10) to obtain $h_{t}$ lead to: 


$$
\begin{aligned}
& x_{t}=\frac{\delta(1+\tau)}{\theta\left[\lambda+(1+\tau) \delta^{2}\right]-\lambda(1+\tau)}\left[\frac{\beta(1+\tau-\theta)\left\{\bar{\theta} \lambda \bar{\Theta}^{2}+\lambda^{2}(1+\tau)\left[(1+\tau) \delta^{2}+\lambda\right] \sigma_{\theta}^{2}\right\} \rho}{\left[\lambda(1+\tau-\bar{\theta})(\beta \rho-1)+\bar{\theta}(1+\tau) \delta^{2}\right] \bar{\Theta}^{2}+(1+\tau)^{2}\left[(1+\tau) \delta^{2}+\lambda\right] \beta \delta^{2} \lambda \rho \sigma_{\theta}^{2}}-\theta\right] e_{t}, \\
& h_{t}=\frac{(1+\tau) \lambda}{\theta\left[\lambda+(1+\tau) \delta^{2}\right]-\lambda(1+\tau)}\left\{\frac{(1-\beta \rho) \bar{\Theta}^{3}}{\left[\lambda(1+\tau-\bar{\theta})(\beta \rho-1)+\bar{\theta}(1+\tau) \delta^{2}\right] \bar{\Theta}^{2}+(1+\tau)^{2}\left[(1+\tau) \delta^{2}+\lambda\right] \beta \delta^{2} \lambda \rho \sigma_{\theta}^{2}}\right\} e_{t} .
\end{aligned}
$$

Examining the effect of interaction between $\rho$ and $\sigma_{\theta}^{2}$ on the sensibility of $\pi_{t}, x_{t}$ and $h_{t}$ to the serially correlated inflation shock leads to the following proposition.

Proposition 7: For given $\tau$, an increase in opacity will induce an increase in the sensibility of inflation and output gap to the serially correlated inflation shock but a decrease in that of model misspecification if $0<\sigma_{\theta}^{2}<\frac{\Xi\left[(1+\tau)\left(\lambda-\bar{\theta} \delta^{2}\right)-\lambda \bar{\theta}\right]^{2}}{(1+\tau)^{2}\left[(1+\tau) \delta^{2}+\lambda\right] \beta \delta^{2} \rho \lambda}$ and $\frac{\beta \rho}{1-\beta \rho}<1+\frac{[\bar{\theta}-(1+\tau)] \lambda}{(1+\tau) \bar{\theta} \delta^{2}}$. The effect of opacity will be reversed either if $\sigma_{\theta}^{2}>\frac{\Xi\left[(1+\tau)\left(\lambda-\bar{\theta} \delta^{2}\right)-\lambda \bar{\theta}\right]^{2}}{(1+\tau)^{2}\left[(1+\tau) \delta^{2}+\lambda\right] \beta \delta^{2} \rho \lambda}$ and $\frac{\beta \rho}{1-\beta \rho}<1+\frac{[\bar{\theta}-(1+\tau)] \lambda}{(1+\tau) \bar{\theta} \delta^{2}}$ or if $\frac{\beta \rho}{1-\beta \rho}>1+\frac{[\bar{\theta}-(1+\tau)] \lambda}{(1+\tau) \bar{\theta} \delta^{2}}, \forall \sigma_{\theta}^{2} \geq 0$

Proof: Deriving twice $\pi_{t}$ given by (50) with respect to $\rho$ and $\sigma_{\theta}^{2}$ leads to:

$$
\begin{aligned}
\frac{\partial^{2} \pi_{t}}{\partial \rho \partial \sigma_{\theta}^{2}}= & \frac{-\lambda^{3} \beta(1+\tau)(1+\tau-\theta)\left[(1+\tau) \delta^{2}+\lambda\right] \bar{\Theta}^{3}}{\theta\left[\lambda+(1+\tau) \delta^{2}\right]-\lambda(1+\tau)} \times \\
& \frac{\left\{\Xi \bar{\Theta}^{2}-(1+\tau)^{2}\left[(1+\tau) \delta^{2}+\lambda\right] \beta \delta^{2} \lambda \rho \sigma_{\theta}^{2}\right\}}{\left\{\left[\lambda(1+\tau-\bar{\theta})(\beta \rho-1)+\bar{\theta}(1+\tau) \delta^{2}\right] \bar{\Theta}^{2}+(1+\tau)^{2}\left[(1+\tau) \delta^{2}+\lambda\right] \beta \delta^{2} \lambda \rho \sigma_{\theta}^{2}\right\}^{3}} e_{t}
\end{aligned}
$$

Using equations (9) and (10), we obtain:

$$
\frac{\partial^{2} x_{t}}{\partial \rho \partial \sigma_{\theta}^{2}}=-\frac{(1+\tau) \delta}{\lambda} \frac{\partial^{2} \pi_{t}}{\partial \rho \partial \sigma_{\theta}^{2}} \text { and } \frac{\partial^{2} h_{t}}{\partial \rho \partial \sigma_{\theta}^{2}}=\frac{(1+\tau)^{2} \delta^{2}}{\lambda(1+\tau-\theta)} \frac{\partial^{2} \pi_{t}}{\partial \rho \partial \sigma_{\theta}^{2}} \text {. }
$$

\footnotetext{
12 We have $\quad \mathrm{E}_{t}\left[\frac{\beta \lambda(1+\tau-\theta) \rho}{\theta\left[\lambda+(1+\tau) \delta^{2}\right]-(1+\tau) \lambda}\right] \approx \beta \lambda(1+\tau-\bar{\theta}) \rho \bar{\Theta}^{-1}+(1+\tau)^{2}\left[(1+\tau) \delta^{2}+\lambda\right] \beta \delta^{2} \lambda \rho \bar{\Theta}^{-3} \sigma_{\theta}^{2} \quad$ and $\mathrm{E}_{t}\left[\frac{\lambda \theta}{\theta\left[\lambda+(1+\tau) \delta^{2}\right]-(1+\tau) \lambda}\right] \approx \bar{\theta} \lambda \bar{\Theta}^{-1}+\lambda^{2}(1+\tau)\left[(1+\tau) \delta^{2}+\lambda\right] \bar{\Theta}^{-3} \sigma_{\theta}^{2}$.
} 
In the above derivatives, we find that one common term determines their sign: i.e. $\Xi=\left\{\bar{\theta}\left[\lambda+(1+\tau) \delta^{2}\right]-\lambda(1+\tau)\right\}(1-\beta \rho)-\bar{\theta}(1+\tau) \beta \delta^{2} \rho$. If $\frac{\beta \rho}{1-\beta \rho}<1+\frac{[\bar{\theta}-(1+\tau)] \lambda}{(1+\tau) \bar{\theta} \delta^{2}}, \quad$ we have $\Xi>0$, and vice versa. Solving then for $\frac{\partial^{2} \pi_{t}}{\partial \rho \partial \sigma_{\theta}^{2}}>0, \frac{\partial^{2} \pi_{t}}{\partial \rho \partial \sigma_{\theta}^{2}}<0, \frac{\partial^{2} x_{t}}{\partial \rho \partial \sigma_{\theta}^{2}}>0, \frac{\partial^{2} x_{t}}{\partial \rho \partial \sigma_{\theta}^{2}}<0, \frac{\partial^{2} h_{t}}{\partial \rho \partial \sigma_{\theta}^{2}}>0$ and $\frac{\partial^{2} h_{t}}{\partial \rho \partial \sigma_{\theta}^{2}}<0$ leads directly to conditions given in Proposition 7.

We have found that, for given $\tau$ and under full transparency, the introduction of a serially correlated inflation shock implies a stronger response of current inflation and output gap to the inflation shock but a weaker response of model misspecification. When we take account of opacity, according to the degree of persistence and the initial degree of opacity, the reaction of these variables could be stronger or weaker.

Substituting the solutions of $\pi_{t}$ and $x_{t}$ given by equations (50) and (51) into the expected social loss function (3) leads to the following single period social loss:

$$
L_{t}^{S}=\frac{1}{2} E_{t}\left\{\begin{array}{l}
\left\{\lambda\left[\frac{\delta(1+\tau)}{\theta\left[\lambda+(1+\tau) \delta^{2}\right]-\lambda(1+\tau)}\right]^{2}+\left[\frac{-\lambda}{\theta\left[\lambda+(1+\tau) \delta^{2}\right]-\lambda(1+\tau)}\right]^{2}\right\} \times \\
{\left[\frac{\beta(1+\tau-\theta)\left\{\bar{\theta} \lambda \bar{\Theta}^{2}+\lambda^{2}(1+\tau)\left[(1+\tau) \delta^{2}+\lambda\right] \sigma_{\theta}^{2}\right\} \rho}{\left[\lambda(1+\tau-\bar{\theta})(\beta \rho-1)+\bar{\theta}(1+\tau) \delta^{2}\right] \bar{\Theta}^{2}+(1+\tau)^{2}\left[(1+\tau) \delta^{2}+\lambda\right] \beta \delta^{2} \lambda \rho \sigma_{\theta}^{2}}-\theta\right]^{2}}
\end{array}\right\} \sigma_{\varepsilon}^{2} .
$$

In the loss function (53), the fraction including $\rho$ is negative since $(1+\tau-\theta)<0$ and $(\beta \rho-1)<0$. The effects of a serially correlated inflation shock on the social loss function under opacity are summarized in the following proposition.

Proposition 8: i) For given $\tau$, an increase in persistence is always associated with higher social loss. ii) When the degree of persistence is small enough, the influence of persistence on the social loss is reinforced by opacity if the initial degree of opacity is sufficiently small and 
vice versa. When the degree of persistence is large enough, an increase in opacity always reduces the effect of persistence on social loss.

Proof: See Appendix B.

Without giving a closed-form solution, we can however conjecture about the effect of a serially correlated inflation shock on the decisions of the government about the optimal inflation targeting weight under opacity.

Central bank opacity and the persistence of inflation shocks, while both increasing the social loss, have opposite effects on the decision of the government about the inflation targeting weight. The first, by increasing the social loss, is sub-optimal for the government and incites the latter to reduce the optimal inflation targeting weight. The second induces the government to make the opposite decision by reinforcing the sensibility of inflation and output gap to the inflation shock and hence their volatility.

The introduction of persistence, by further increasing the social loss, will not substantially modify the nature of the government's decision problem but can change the level of the effects of opacity on the optimal inflation targeting weight.

The second part of Proposition 8 suggests that an increase in opacity allows reducing the effect of persistence on social loss when the degree of persistence is large. It implies that high persistence of inflation shocks might increase the incentive for the central bank to be more opaque in order to induce the government to reduce the inflation targeting weight.

\section{Conclusion}


In this paper, we have examined the accountability issue in a framework of delegation where government and private agents are subject to uncertainty about the preference for model robustness of the central bank, while the latter faces model uncertainty. More precisely, we have studied the implications of these two kinds of uncertainty for the accountability of the central bank as well as for macroeconomic performance and volatility.

If the inflation shock is serially uncorrelated, in the benchmark case of full transparency and in the absence of robust control, it is not necessary to impose any penalty. This result is explained by the fact that we do not introduce an inflation bias in the loss function of the central bank.

If the central bank uses robust control techniques in monetary policy decision, any increase in the preference for model robustness leads to a lower inflation targeting weight. Our results imply that the government should appoint a liberal central banker, which is the opposite of the finding of Rogoff (1985). More uncertain the central bank is about its model, less weight the central bank should assign on inflation under optimal delegation.

For every given level of inflation targeting weight, an increase in opacity deteriorates the social welfare since opacity induces a higher volatility of inflation and output gap. The central bank which lacks goal independence in the framework of delegation may try to gain more independence by being opaque about its preference for model robustness. Under opacity, the government may be induced to decrease the inflation targeting weight in order to favour a reduction in model robustness.

The macroeconomic performance depends on the relationship between the inflation targeting weight and the degree of opacity. As this relationship is negative for a small initial degree of opacity, more opacity increases the sensibility of inflation and model misspecification to the inflation shock but reduces that of output gap. In terms of macroeconomic volatility, we have shown that the volatility of inflation, model 
misspecification and output gap could be increased or decreased if the initial degree of opacity is higher enough. Under some conditions, there could be cases for more opacity.

Finally, if the inflation shock is serially correlated, our study suggests that the inflation targeting weight increases with the persistence of shock under full transparency. It implies a stronger response of current inflation and output gap but a weaker response of model misspecification to the inflation shock. An increase in opacity will induce an increase in the sensibility of inflation and output gap to the inflation shock but a decrease in that of model misspecification if the initial degree of opacity and the degree of persistence are both small enough. If the persistence is sufficiently high, the effect of opacity could be reversed independently of the initial degree of opacity. An increase in persistence is always associated with higher social loss and its influence could be reinforced by an increase in opacity if the initial degree of opacity is sufficiently small and inversely. When the degree of persistence is large enough, an increase in opacity always reduces the effect of persistence on social loss. These results suggest that the effects of opacity on the optimal inflation targeting weight could be reinforced or weakened according to the initial degree of opacity and/or degree of persistence.

\section{Appendix A: Demonstration of the condition under which $\frac{\partial \tau}{\partial \sigma_{\theta}^{2}}<0$ (Proposition 3)}

Denote $T=(1+\tau)$. The second-order Taylor approximation of the expected social loss function (31) is given as follows:

$$
\begin{aligned}
L_{t}^{S} \approx & \frac{1}{2}\left\{\frac{\left(\lambda \bar{\theta}^{2} \delta^{2} T^{2}+\bar{\theta}^{2} \lambda^{2}\right)}{\left[\bar{\theta}\left(\lambda+T \delta^{2}\right)-T \lambda\right]^{2}}\right\} E_{t}\left(e_{t}\right)^{2}+ \\
& +\frac{1}{2}\left\{\frac{\left(\delta^{2} T^{2}+\lambda\right)\left[T^{2} \lambda^{3}+2 T \bar{\theta} \lambda^{2}\left(\lambda+T \delta^{2}\right)\right]}{\left[\bar{\theta}\left(\lambda+T \delta^{2}\right)-T \lambda\right]^{4}}\right\} E_{t}\left(e_{t}\right)^{2} \sigma_{\theta}^{2} .
\end{aligned}
$$

The first-order condition of the government minimization problem is: 


$$
\begin{aligned}
& \frac{\partial L_{t}^{S}}{\partial \tau} \approx \frac{1}{2}\left\{\frac{2 \lambda \bar{\theta}^{2} \delta^{2} T\left[\bar{\theta}\left(\lambda+T \delta^{2}\right)-T \lambda\right]-2\left(\lambda \bar{\theta}^{2} \delta^{2} T^{2}+\bar{\theta}^{2} \lambda^{2}\right)\left(\bar{\theta} \delta^{2}-\lambda\right)}{\left[\bar{\theta}\left(\lambda+T \delta^{2}\right)-T \lambda\right]^{3}}\right\} E_{t}\left(e_{t}\right)^{2}+ \\
& +\frac{1}{2} \frac{\left[\begin{array}{l}
\left\{\begin{array}{l}
2 \delta^{2} T\left[T^{2} \lambda^{3}+2 T \bar{\theta} \lambda^{2}\left(\lambda+T \delta^{2}\right)\right] \\
+\left(\delta^{2} T^{2}+\lambda\right)\left[2 T \lambda^{3}+2 \bar{\theta} \lambda^{2}\left(\lambda+T \delta^{2}\right)+2 T \bar{\theta} \lambda^{2} \delta^{2}\right]
\end{array}\right. \\
-4\left(\delta^{2} T^{2}+\lambda\right)\left[T^{2} \lambda^{3}+2 T \bar{\theta} \lambda^{2}\left(\lambda+T \delta^{2}\right)\right]\left(\bar{\theta} \delta^{2}-\lambda\right)
\end{array}\right]}{\left[\bar{\theta}\left(\lambda+T \delta^{2}\right)-T \lambda\right]^{5}} E_{t}\left(e_{t}\right)^{2} \sigma_{\theta}^{2} .
\end{aligned}
$$

Simplifying successively without breaking the term $\left(\bar{\theta} \delta^{2}-\lambda\right)$ leads to:

$$
\begin{aligned}
& \frac{\partial L_{t}^{S}}{\partial \tau} \approx\left\{\frac{\lambda^{2} \bar{\theta}^{2}\left[\delta^{2} \bar{\theta} T-\left(\bar{\theta} \delta^{2}-\lambda\right)\right]}{\left[\bar{\theta}\left(\lambda+T \delta^{2}\right)-T \lambda\right]^{3}}\right\} E_{t}\left(e_{t}\right)^{2}+ \\
& +\frac{\left\{\begin{array}{l}
\left(2 \delta^{2} \lambda^{3}+4 \delta^{4} \lambda^{2} \bar{\theta}\right) T^{3}+3 \delta^{2} \lambda^{3} \bar{\theta} T^{2} \\
+\left(2 \delta^{2} \lambda^{3} \bar{\theta}+\lambda^{4}\right) T+\lambda^{4} \bar{\theta}
\end{array}\right\} \bar{\theta} \lambda+\left\{\begin{array}{l}
-\delta^{2} \lambda^{3} \bar{\theta} T^{2} \\
-\left(2 \delta^{2} \lambda^{3} \bar{\theta}+\lambda^{4}\right) T \\
-3 \lambda^{4} \bar{\theta}
\end{array}\right\} T\left(\bar{\theta} \delta^{2}-\lambda\right)}{\left[\bar{\theta}\left(\lambda+T \delta^{2}\right)-T \lambda\right]^{5}} E_{t}\left(e_{t}\right)^{2} \sigma_{\theta}^{2} .
\end{aligned}
$$

According to equation (11), we have $\theta>1+\tau=T$. That implies $-T \lambda+\theta\left(\lambda+T \delta^{2}\right)>0$. Multiplying condition (A.2) by $\left[\bar{\theta}\left(\lambda+T \delta^{2}\right)-T \lambda\right]^{5}$ and eliminating $E\left(e_{t}\right)^{2}$, we can rewrite equivalently condition (A.2) as:

$$
\begin{aligned}
\Gamma= & \lambda^{2} \bar{\theta}^{2}\left[\delta^{2} \bar{\theta} T-\left(\bar{\theta} \delta^{2}-\lambda\right)\right]\left[\bar{\theta}\left(\lambda+T \delta^{2}\right)-T \lambda\right]^{2}+ \\
& \left.+\left\{\begin{array}{l}
\left(2 \delta^{2} \lambda^{3}+4 \delta^{4} \lambda^{2} \bar{\theta}\right) T^{3} \\
+3 \delta^{2} \lambda^{3} \bar{\theta} T^{2} \\
+\left(2 \delta^{2} \lambda^{3} \bar{\theta}+\lambda^{4}\right) T+\lambda^{4} \bar{\theta}
\end{array}\right] \bar{\theta} \lambda+\left[\begin{array}{l}
-\delta^{2} \lambda^{3} \bar{\theta}\left(\bar{\theta} \delta^{2}-\lambda\right) T^{3} \\
-\left(2 \delta^{2} \lambda^{3} \bar{\theta}+\lambda^{4}\right)\left(\bar{\theta} \delta^{2}-\lambda\right) T^{2} \\
-3 \lambda^{4} \bar{\theta}\left(\bar{\theta} \delta^{2}-\lambda\right) T
\end{array}\right]\right\} \sigma_{\theta}^{2}=0 .
\end{aligned}
$$

According to the implicit function theorem, totally differentiating (A.3) leads to

$$
\frac{\partial \Gamma}{\partial \tau} d \tau+\frac{\partial \Gamma}{\partial \sigma_{\theta}^{2}} d \sigma_{\theta}^{2}=0
$$

where

$$
\frac{\partial \Gamma}{\partial \sigma_{\theta}^{2}}=\left[\begin{array}{l}
\left(2 \delta^{2} \lambda^{3}+4 \delta^{4} \lambda^{2} \bar{\theta}\right) T^{3} \\
+3 \delta^{2} \lambda^{3} \bar{\theta} T^{2} \\
+\left(2 \delta^{2} \lambda^{3} \bar{\theta}+\lambda^{4}\right) T+\lambda^{4} \bar{\theta}
\end{array}\right] \bar{\theta} \lambda+\left[\begin{array}{l}
-\delta^{2} \lambda^{3} \bar{\theta}\left(\bar{\theta} \delta^{2}-\lambda\right) T^{3} \\
-\left(2 \delta^{2} \lambda^{3} \bar{\theta}+\lambda^{4}\right)\left(\bar{\theta} \delta^{2}-\lambda\right) T^{2} \\
-3 \lambda^{4} \bar{\theta}\left(\bar{\theta} \delta^{2}-\lambda\right) T
\end{array}\right]
$$




$$
\begin{aligned}
& \frac{\partial \Gamma}{\partial \tau}=\delta^{2} \lambda^{2} \bar{\theta}^{3}\left[\bar{\theta}\left(\lambda+T \delta^{2}\right)-T \lambda\right]^{2}+2 \lambda^{2} \bar{\theta}^{2}\left[\delta^{2} \bar{\theta} T-\left(\bar{\theta} \delta^{2}-\lambda\right)\right]\left[\bar{\theta}\left(\lambda+T \delta^{2}\right)-T \lambda\right]\left(\bar{\theta} \delta^{2}-\lambda\right) \\
& \quad+\left[\begin{array}{l}
3\left(2 \delta^{2} \lambda^{3}+4 \delta^{4} \lambda^{2} \bar{\theta}\right) T^{2} \\
+6 \delta^{2} \lambda^{3} \bar{\theta} T \\
+\left(2 \delta^{2} \lambda^{3} \bar{\theta}+\lambda^{4}\right)
\end{array}\right] \bar{\theta} \lambda+\left[\begin{array}{l}
-3 \delta^{2} \lambda^{3} \bar{\theta}\left(\bar{\theta} \delta^{2}-\lambda\right) T^{2} \\
-2\left(2 \delta^{2} \lambda^{3} \bar{\theta}+\lambda^{4}\right)\left(\bar{\theta} \delta^{2}-\lambda\right) T \\
-3 \lambda^{4} \bar{\theta}\left(\bar{\theta} \delta^{2}-\lambda\right)
\end{array}\right] \sigma_{\theta}^{2}
\end{aligned}
$$

Condition (A.4) and equations (A.5) and (A.6) allow us to find the relationship between the penalty ( $\tau$ ) and the degree of opacity $\left(\sigma_{\theta}^{2}\right)$.

$$
\begin{gathered}
\frac{\partial \tau}{\partial \sigma_{\theta}^{2}}=-\frac{\frac{\partial \Gamma}{\partial \sigma_{\theta}^{2}}}{\frac{\partial \Gamma}{\partial \tau}}=-\frac{\left[\begin{array}{l}
\left(2 \delta^{2} \lambda^{3}+4 \delta^{4} \lambda^{2} \bar{\theta}\right) T^{3} \\
+3 \delta^{2} \lambda^{3} \bar{\theta} T^{2} \\
+\left(2 \delta^{2} \lambda^{3} \bar{\theta}+\lambda^{4}\right) T+\lambda^{4} \bar{\theta}
\end{array}\right]\left[\begin{array}{l}
-\delta^{2} \lambda^{3} \bar{\theta}\left(\bar{\theta} \delta^{2}-\lambda\right) T^{3} \\
-\left(2 \delta^{2} \lambda^{3} \bar{\theta}+\lambda^{4}\right)\left(\bar{\theta} \delta^{2}-\lambda\right) T^{2} \\
-3 \lambda^{4} \bar{\theta}\left(\bar{\theta} \delta^{2}-\lambda\right) T
\end{array}\right]}{\delta^{2} \lambda^{2} \bar{\theta}^{3}\left[\bar{\theta}\left(\lambda+T \delta^{2}\right)-T \lambda\right]^{2}+2 \lambda^{2} \bar{\theta}^{2}\left[\delta^{2} \bar{\theta} T-\left(\bar{\theta} \delta^{2}-\lambda\right) \mathbf{I} \bar{\theta}\left(\lambda+T \delta^{2}\right)-T \lambda\right]\left(\bar{\theta} \delta^{2}-\lambda\right)} \\
+\left[\begin{array}{l}
3\left(2 \delta^{2} \lambda^{3}+4 \delta^{4} \lambda^{2} \bar{\theta}\right) T^{2} \\
+6 \delta^{2} \lambda^{3} \bar{\theta} T \\
+\left(2 \delta^{2} \lambda^{3} \bar{\theta}+\lambda^{4}\right)
\end{array}\right] \bar{\theta} \lambda+\left[\begin{array}{l}
-3 \delta^{2} \lambda^{3} \bar{\theta}\left(\bar{\theta} \delta^{2}-\lambda\right) T^{2} \\
-2\left(2 \delta^{2} \lambda^{3} \bar{\theta}+\lambda^{4}\right)\left(\bar{\theta} \delta^{2}-\lambda\right) T \\
-3 \lambda^{4} \bar{\theta}\left(\bar{\theta} \delta^{2}-\lambda\right)
\end{array}\right] \sigma_{\theta}^{2}
\end{gathered}
$$

In the following, we only examine the solution obtained at the equilibrium where the initial value of opacity is zero (i.e. $\sigma_{\theta}^{2}=0$ ). Since the optimal solution for the inflation targeting weight is $\tau=-\frac{\lambda}{\bar{\theta} \delta^{2}}$ at equilibrium, so that $T=1+\tau=1-\frac{\lambda}{\bar{\theta} \delta^{2}}=\frac{\bar{\theta} \delta^{2}-\lambda}{\bar{\theta} \delta^{2}}$ and consequently $\left(\bar{\theta} \delta^{2}-\lambda\right)=\delta^{2} \bar{\theta} T$. Using the condition $\sigma_{\theta}^{2}=0$ and substituting $\left(\bar{\theta} \delta^{2}-\lambda\right)$ by $\delta^{2} \bar{\theta} T$ into (A.7) except for the term $\delta^{2} \lambda^{3} \bar{\theta}\left(\bar{\theta} \delta^{2}-\lambda\right) T^{3}$ lead to:

$$
\frac{\partial \tau}{\partial \sigma_{\theta}^{2}}=-\frac{\left(2 \lambda+\delta^{2} \bar{\theta}\right) \delta^{2} \lambda^{3} \bar{\theta} T^{3}+\left(\lambda+2 \delta^{2} \bar{\theta}\right) \lambda^{4} \bar{\theta} T+\lambda^{5} \bar{\theta}^{2}}{\delta^{2} \lambda^{2} \bar{\theta}^{3}\left[\bar{\theta}\left(\lambda+T \delta^{2}\right)-T \lambda\right]^{2}}<0
$$

where $\bar{\theta}>\frac{\lambda}{\delta^{2}}$ since for $\sigma_{\theta}^{2}=0$, we have $\tau=\frac{-\lambda}{\bar{\theta} \delta^{2}}$ and $1+\tau>0$.

Q.E.D.

\section{Appendix B: Proof of Proposition 8}

Denoting $T=1+\tau$ and deriving $L_{t}^{S}$ given by equation (53), we obtain: 


$$
\frac{\partial L_{t}^{S}}{\partial \rho}=\left\{\begin{array}{l}
E\left[\frac{\left.(T-\theta)^{2}\left(T^{2} \lambda \delta^{2}+\lambda^{3}\right)\right]}{\left[\theta\left(1+T \delta^{2}\right)-\lambda T\right]^{2}}\right] \beta^{2}\left\{\lambda \bar{\theta}\left[\bar{\theta}\left(1+T \delta^{2}\right)-\lambda T\right]^{2}+T \lambda^{2}\left(T \delta^{2}+\lambda\right) \sigma_{\theta}^{2}\right\}^{2} \rho \\
\times\left[\frac{\left[\bar{\theta}\left(1+T \delta^{2}\right)-\lambda T\right]^{3}}{\left\{\left[\lambda(T-\bar{\theta})(\beta \rho-1)+T \bar{\theta} \delta^{2}\right]\left[\bar{\theta}\left(1+T \delta^{2}\right)-\lambda T\right]^{2}+T^{2}\left(T \delta^{2}+\lambda\right) \beta \lambda \delta^{2} \rho \sigma_{\theta}^{2}\right\}^{3}}\right] \\
-E\left[\frac{\theta(T-\theta)\left(T^{2} \lambda \delta^{2}+\lambda^{3}\right)}{\left[\theta\left(1+T \delta^{2}\right)-\lambda T\right]^{2}}\right] \times \beta\left\{\lambda \bar{\theta}\left[\bar{\theta}\left(1+T \delta^{2}\right)-\lambda T\right]^{2}+T \lambda^{2}\left(T \delta^{2}+\lambda\right) \sigma_{\theta}^{2}\right\}
\end{array}\right] \sigma_{e}^{2}>0 .
$$

Since $E\left[\frac{\theta(T-\theta)\left(T^{2} \lambda \delta^{2}+\lambda^{3}\right)}{\left[\theta\left(1+T \delta^{2}\right)-\lambda T\right]^{2}}\right]<0$ and other terms are all positive, it is easy to check that $\frac{\partial L_{t}^{S}}{\partial \rho}>0$, i.e. the effect of an increase in $\rho$ on $L_{t}^{S}$ is always positive.

Deriving $\frac{\partial L_{t}^{S}}{\partial \rho}$ with respect to $\sigma_{\theta}^{2}$ yields:

$\frac{\partial^{2} L_{t}^{S}}{\partial \rho \partial \sigma_{\theta}^{2}}=\frac{\left[\bar{\theta}\left(1+T \delta^{2}\right)-\lambda T\right]^{3}}{\left\{\left[\lambda(T-\bar{\theta})(\beta \rho-1)+T \bar{\theta} \delta^{2}\right]\left[\bar{\theta}\left(1+T \delta^{2}\right)-\lambda T\right]^{2}+T^{2}\left(T \delta^{2}+\lambda\right) \beta \lambda \delta^{2} \rho \sigma_{\theta}^{2}\right\}^{4}} \times$
$\left\{\begin{array}{l}E\left[\frac{(T-\theta)^{2}\left(T^{2} \lambda \delta^{2}+\lambda^{3}\right)}{\left[\theta\left(1+T \delta^{2}\right)-\lambda T\right]^{2}}\right] \beta^{2} \rho T \lambda^{2}\left\{\lambda \bar{\theta}\left[\bar{\theta}\left(1+T \delta^{2}\right)-\lambda T\right]^{2}+T \lambda^{2}\left(T \delta^{2}+\lambda\right) \sigma_{\theta}^{2}\right\}\left(T \delta^{2}+\lambda\right) \times \\ \left\{\left[2 \lambda(T-\bar{\theta})(\beta \rho-1)+\delta^{2} \bar{\theta} T(2-3 \beta \rho)\right]\left[\bar{\theta}\left(1+T \delta^{2}\right)-\lambda T\right]^{2}-\beta \delta^{2} \rho \lambda T^{2}\left(T \delta^{2}+\lambda\right) \sigma_{\theta}^{2}\right\} \\ -E\left[\frac{\theta(T-\theta)\left(T^{2} \lambda \delta^{2}+\lambda^{3}\right)}{\left[\theta\left(1+T \delta^{2}\right)-\lambda T\right]^{2}}\right] \beta\left\{\left[\lambda(T-\bar{\theta})(\beta \rho-1)+T \bar{\theta} \delta^{2}\right]\left[\bar{\theta}\left(1+T \delta^{2}\right)-\lambda T\right]^{2}+T^{2}\left(T \delta^{2}+\lambda\right) \beta \lambda \delta^{2} \rho \sigma_{\theta}^{2}\right\} T \lambda^{2}\left(T \delta^{2}+\lambda\right) \times \\ \left\{\left[\lambda(T-\bar{\theta})(\beta \rho-1)+\bar{\theta} T \delta^{2}(1-2 \beta \rho)\right]\left[\bar{\theta}\left(1+T \delta^{2}\right)-\lambda T\right]^{2}-T^{2}\left(T \delta^{2}+\lambda\right) \beta \lambda \delta^{2} \rho \sigma_{\theta}^{2}\right\}\end{array}\right\} \sigma_{e}^{2}$.

The sign of $\frac{\partial^{2} L_{t}^{S}}{\partial \rho \partial \sigma_{\theta}^{2}}$ is easy to determine if the following expressions have the same sign:

1) $K_{1}=\left[2 \lambda(T-\bar{\theta})(\beta \rho-1)+\delta^{2} \bar{\theta} T(2-3 \beta \rho)\right]\left[\bar{\theta}\left(1+T \delta^{2}\right)-\lambda T\right]^{2}-\beta \delta^{2} \rho \lambda T^{2}\left(T \delta^{2}+\lambda\right) \sigma_{\theta}^{2}$;

2) $K_{2}=\left[\lambda(T-\bar{\theta})(\beta \rho-1)+\bar{\theta} T \delta^{2}(1-2 \beta \rho)\right]\left[\bar{\theta}\left(1+T \delta^{2}\right)-\lambda T\right]^{2}-T^{2}\left(T \delta^{2}+\lambda\right) \beta \lambda \delta^{2} \rho \sigma_{\theta}^{2}$.

If $K_{1}$ and $K_{2}$ have opposite sign, it will be difficult to give a closed-form conditions under which the sign of $\frac{\partial^{2} L_{t}^{S}}{\partial \rho \partial \sigma_{\theta}^{2}}$ is well specified.

Solving for $K_{1}, K_{2}>0$, we find that $\frac{\partial^{2} L_{t}^{S}}{\partial \rho \partial \sigma_{\theta}^{2}}>0$ if the following conditions are verified:

1) $0<\rho<\frac{-\lambda(T-\bar{\theta})+T \bar{\theta} \delta^{2}}{\beta\left[-\lambda(T-\bar{\theta})+2 T \bar{\theta} \delta^{2}\right]}$, and 
2) $\sigma_{\theta}^{2}<\frac{\left[\bar{\theta}\left(1+T \delta^{2}\right)-\lambda T\right]^{2}}{T^{2}\left(T \delta^{2}+\lambda\right) \beta \lambda \delta^{2} \rho} \times \min \left\{\begin{array}{l}{\left[2 \lambda(T-\bar{\theta})(\beta \rho-1)+(2-3 \beta \rho) T \bar{\theta} \delta^{2}\right]^{2} ;} \\ {\left[\lambda(T-\bar{\theta})(\beta \rho-1)+(1-2 \beta \rho) T \bar{\theta} \delta^{2}\right]}\end{array}\right\}$.

Solving for $K_{1}, K_{2}<0$, we obtain $\frac{\partial^{2} L_{t}^{S}}{\partial \rho \partial \sigma_{\theta}^{2}}<0$ if the following conditions are verified:

1) $0<\rho<\frac{-\lambda(T-\bar{\theta})+T \bar{\theta} \delta^{2}}{\beta\left[-\lambda(T-\bar{\theta})+2 T \bar{\theta} \delta^{2}\right]}$, and

2) $\sigma_{\theta}^{2}<\frac{\left[\bar{\theta}\left(1+T \delta^{2}\right)-\lambda T\right]^{2}}{T^{2}\left(T \delta^{2}+\lambda\right) \beta \lambda \delta^{2} \rho} \times \max \left\{\begin{array}{l}{\left[2 \lambda(T-\bar{\theta})(\beta \rho-1)+(2-3 \beta \rho) T \bar{\theta} \delta^{2}\right]^{2} ;} \\ {\left[\lambda(T-\bar{\theta})(\beta \rho-1)+(1-2 \beta \rho) T \bar{\theta} \delta^{2}\right]}\end{array}\right\}$.

Furthermore, examining $K_{1}$ and $K_{2}$, we find that the first term in these two expressions will be negative if the persistence of inflation shock is sufficiently high, i.e.:

$$
0<\frac{-\lambda(T-\bar{\theta})+T \bar{\theta} \delta^{2}}{\beta\left[-\lambda(T-\bar{\theta})+1.5 T \bar{\theta} \delta^{2}\right]}<\rho, \text { for } \forall \sigma_{\theta}^{2}
$$

Under the above condition, we also have $K_{1}, K_{2}<0$ and hence $\frac{\partial^{2} L_{t}^{S}}{\partial \rho \partial \sigma_{\theta}^{2}}<0$ Q.E.D.

\section{References:}

Barro, R. and Gordon D. (1983), "A Positive Theory of Monetary Policy in a Natural Rate Model,” Journal of Political Economy, Vol. 91, 589-610.

Beetsma, M. W. J. R. and Jensen H. (1998), "Inflation targets and contracts with uncertain central banker preferences,” Journal of Money Credit and Banking, Vol. 30, 384-403.

Chortareas, G., D. Stasavage, and G. Stern (2002), "Does it pay to be transparent? International evidence from central bank forecasts," Federal Reserve Bank of St. Louis Review 84, iss. 4, 99-117.

Chortareas, Georgios E. and Stephen M. Miller (2003), "Central Banker Contracts, Incomplete Information, and Monetary Policy Surprises: In Search of a Selfish Central Banker?” Public Choice, Vol. 116(3-4), 271-95.

Clarida R., Gali J. and Gertler M. (1999), “The science of monetary policy: a new Keynesian Perspective,” Journal of Economic Literature, Vol. 37, 1661-1707.

Cukierman, Alex (2002), “Are Contemporary Central Banks Transparent About Economic Models and Objectives and What Difference Does It Make?” The Federal Reserve Bank of St. Louis Review, Vol. 84, No. 4, 15-36.

Cukierman, Alex and Meltzer, Allan H. (1986), “A Theory of Ambiguity, Credibility, and Inflation under Discretion and Asymmetric Information.” Econometrica, 54(5), 1099-28.

Demertzis, Maria, A. Hughes Hallet (2007), "Central Bank Transparency in Theory and Practice,” Journal of Macroeconomics, Volume 29, Issue 4, 760-789.

Dincer, N. Nergiz and Eichengreen, Barry (2007), "Central Bank Transparency: Where, Why and with What Effects?” NBER Working Paper No. 13003. 
Eijffinger, Sylvester C. W. and Mewael F. Tesfaselassie (2007), "Central Bank Forecasts and Disclosure Policy: Why it Pays to be Optimistic," European Journal of Political Economy, Vol. 23, Iss. 1, 30-50.

Faust, J. and L. E. O. Svensson (2001), “Transparency and Credibility: Monetary Policy with Unobservable Goals,” International Economic Review 42, 369-07.

Faust, J. and L. E. O. Svensson (2001), Eijffinger, Sylvester C. W. and Geraats, Petra M. (2006), “How transparent are Central Banks?” European Journal of Political Economy, vol. 22, iss. 1, 1-21.

Geraats, Petra (2002), “Central Bank Transparency,” The Economic Journal, 112, 532-565.

Giannoni, Marc and Michael Woodford (2003a), "Optimal Interest-Rate Rules: I. General Theory,” NBER Working Paper No. 9419.

Giannoni, Marc and Michael Woodford (2003b), “Optimal Interest-Rate Rules: II. Applications,” NBER Working Paper No. 9420.

Giannoni, Marc P. (2002), "Does Model Uncertainty Justify Caution? Robust Optimal Monetary Policy in a Forward-Looking Model,” Macroeconomic Dynamics, Vol. 6(1), 111-44.

Giannoni, Marc P. (2007), "Robust optimal monetary policy in a forward-looking model with parameter and shock uncertainty,” Journal of Applied Econometrics, Vol. 22(1), 179-213.

Hansen, Lars Peter and Thomas J. Sargent (2003), "Robust Control of Forward-Looking Models,” Journal of Monetary Economics, 50, 581-604.

Hansen, Lars Peter and Thomas J. Sargent (2007), Robustness, Princeton University Press, New York.

Hughes Hallett, A., and D. N. Weymark (2005): "Independence before Conservatism: Transparency, Politics and Central Bank Design”, German Economic Review, 6, 1-21.

Hughes Hallett, Andrew and Jan Libich (2009), "Explicit Inflation Targets, Communication, and Central Bank Independence: Friends or Foes?” Mimeo.

Jensen, Henrik (2002), "Optimal Degrees of Transparency in Monetary Policymaking," Scandinavian Journal of Economics 104(3), 399-422.

Kilponen, Juha (2003), “A positive theory of monetary policy and robust control,” Bank of Finland Discussion Papers $\mathrm{N}^{\circ}$ 18.2003.

Leitemo, Kai and Ulf Söderström (2008), "Robust Monetary Policy in the New Keynesian Framework,” Macroeconomic Dynamics, Vol. 12, Supplement S1, pp 126-135.

Levin, Andrew T. and John C. Williams (2003), "Robust monetary policy with competing reference models,” Journal of Monetary Economics, Vol. 50, Issue 5, 945-975.

McCallum, Bennet T. (1983), “On non-uniqueness in rational expectations models: An attempt at perspective,” Journal of Monetary Economics, 11(2), 139-68.

McCallum, Bennett (1999), "Issues in the Design of Monetary Policy Rules,” in John B. Taylor and Michael Woodford (Eds), Handbook of Macroeconomics, North-Holland.

Muscatelli, A. (1998), "Optimal inflation contracts and inflation targets with uncertain central bank preferences: Accountability through independence?” The Economic Journal 108, 529542.

Nolan, C. and E. Schaling (1998), "Monetary Policy Uncertainty and Inflation: The Role of Central Bank Accountability,” De Economist 146, 585-602.

Onatski, Alexei and James H. Stock (2002) "Robust Monetary Policy under Model Uncertainty in a Small Model of the U.S. Economy," Macroeconomic Dynamics, Vol. 6 (1), 85-110.

Rogoff, Kenneth (1985), "The Optimal Degree of Commitment to an Intermediate Monetary Target,” Quarterly Journal of Economics 100, 1169-1189. 
Svensson, Lars E. O. and Michael Woodford (2004), "Implementing Optimal Policy through Inflation-Forecast Targeting." In Ben S. Bernanke and Michael Woodford (ed.), The Inflation Targeting Debate. Chicago: University of Chicago Press.

Svensson, Lars E.O. (1997), “Optimal Inflation Targets, 'Conservative’ Central Banks, and Linear Inflation Contracts,” American Economic Review 87, 98-114.

Walsh, Carl E. (1995), “Optimal Contracts for Central Bankers,” American Economic Review 85, 150-167.

Walsh, Carl E. (2003), “Accountability, Transparency, and Inflation Targeting,” Journal of Money, Credit, and Banking, 35(5), 829-849.

Walsh, Carl E. (2004), "Robustly Optimal Instrument Rules and Robust Control: An Equivalence Result,” Journal of Money, Credit, and Banking, 36(6), 1105-1113. 